ARTICLE

DOI: 10.1038/s41467-017-01313-w

\title{
Reconstitution of human shelterin complexes reveals unexpected stoichiometry and dual pathways to enhance telomerase processivity
}

\author{
Ci Ji Lim¹,2, Arthur J. Zaug1,2, Hee Jin Kim¹,2 \& Thomas R. Cech (1) 1,2
}

\begin{abstract}
The human shelterin proteins associate with telomeric DNA to confer telomere protection and length regulation. They are thought to form higher-order protein complexes for their functions, but studies of shelterin proteins have been mostly limited to pairs of proteins. Here we co-express various human shelterin proteins and find that they form defined multi-subunit complexes. A complex harboring both TRF2 and POT1 has the strongest binding affinity to telomeric DNA substrates comprised of double-stranded DNA with a $3^{\prime}$ single-stranded extension. TRF2 interacts with TIN2 with an unexpected 2:1 stoichiometry in the context of shelterin (RAP1 $\left.: \mathrm{TRF}_{2}: \mathrm{TIN2}_{1}: \mathrm{TPP}_{1}: \mathrm{POT}_{1}\right)$. Tethering of TPP1 to the telomere either via TRF2-TIN2 or via POT1 gives equivalent enhancement of telomerase processivity. We also identify a peptide region from TPP1 that is both critical and sufficient for TIN2 interaction. Our findings reveal new information about the architecture of human shelterin and how it performs its functions at telomeres.
\end{abstract}

\footnotetext{
${ }^{1}$ Howard Hughes Medical Institute, University of Colorado BioFrontiers Institute, Boulder, CO 80309, USA. ${ }^{2}$ Department of Chemistry \& Biochemistry, University of Colorado, Boulder, CO 80309, USA. Correspondence and requests for materials should be addressed to

T.R.C. (email: Thomas.Cech@colorado.edu)
} 
T he human shelterin proteins are essential to protect the telomere ends from being recognized as damaged DNA sites and also serve to regulate telomere length, in conjunction with telomerase ${ }^{1}$. The removal or knockdown of shelterin proteins-TRF1, TRF2, RAP1, TIN2, TPP1, and POT1-can result in chromosome end fusions, leading to genome instability ${ }^{2}$, or failure to regulate telomerase recruitment and telomere maintenance 3,4 . Indeed, single amino-acid mutants or deletion variants of TPP $1^{5}$ and TIN $2{ }^{6}$ fail to recruit telomerase in humans, leading to telomere shortening and dyskeratosis congenita.

The shelterin proteins are known to interact with each other, mostly through binary interaction studies, and have been proposed to form a higher-order multi-subunit protein complex (known as either shelterin or telosome) ${ }^{1,7,8}$. TRF1 and TRF2 are homodimers $^{9-11}$ and have a C-terminal DNA-binding Myb domain that binds specifically to telomeric duplex YTAGGGTTR repeats $^{10,12}$. The TRF proteins serve as the foundation for shelterin assembly at telomeres. Both TRF proteins interact with TIN2, which serves to enhance TRF2 stability at telomeres ${ }^{13}, 14$. TPP1 is recruited to telomeres via TIN $2^{7}, 15$. The TIN2-TPP1 interaction is suggested to be the foundation for forming higher-order shelterin complexes ${ }^{7}$. POT1, the chromosome endcapping protein ${ }^{16}$, has two oligonucleotide/oligosaccharidebinding (OB)-folds that bind single-stranded telomeric DNA, TTAGGGTTAG ${ }^{17,18}$, but it depends on its interaction with TPP1 for recruitment to telomeres in cells 19,20 . Rap1 is recruited to telomeres via interaction with TRF2 21,22 .

For shelterin protection of chromosome ends, TRF2 serves as the main antagonist to inappropriate recognition of DNA damage at telomeres by the ATM kinase pathway 1, 2, 23-25, while POT1 blocks activation of the ATR kinase pathway at the singlestranded telomeric region ${ }^{25}$. Concerning shelterin recruitment of telomerase, TPP1 binds telomerase ${ }^{26}$ via the TPP1 TEL-patch ${ }^{5}$ and TERT (telomerase reverse transcriptase) TEN domain ${ }^{27}$. In

a Shelterin complexes
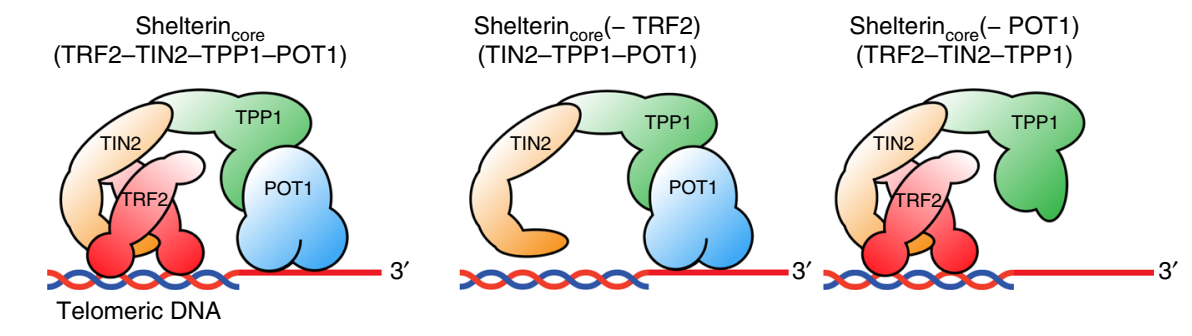

Shelterin $_{\text {core }}(-\mathrm{POT} 1)$ (TRF2-TIN2-TPP1)
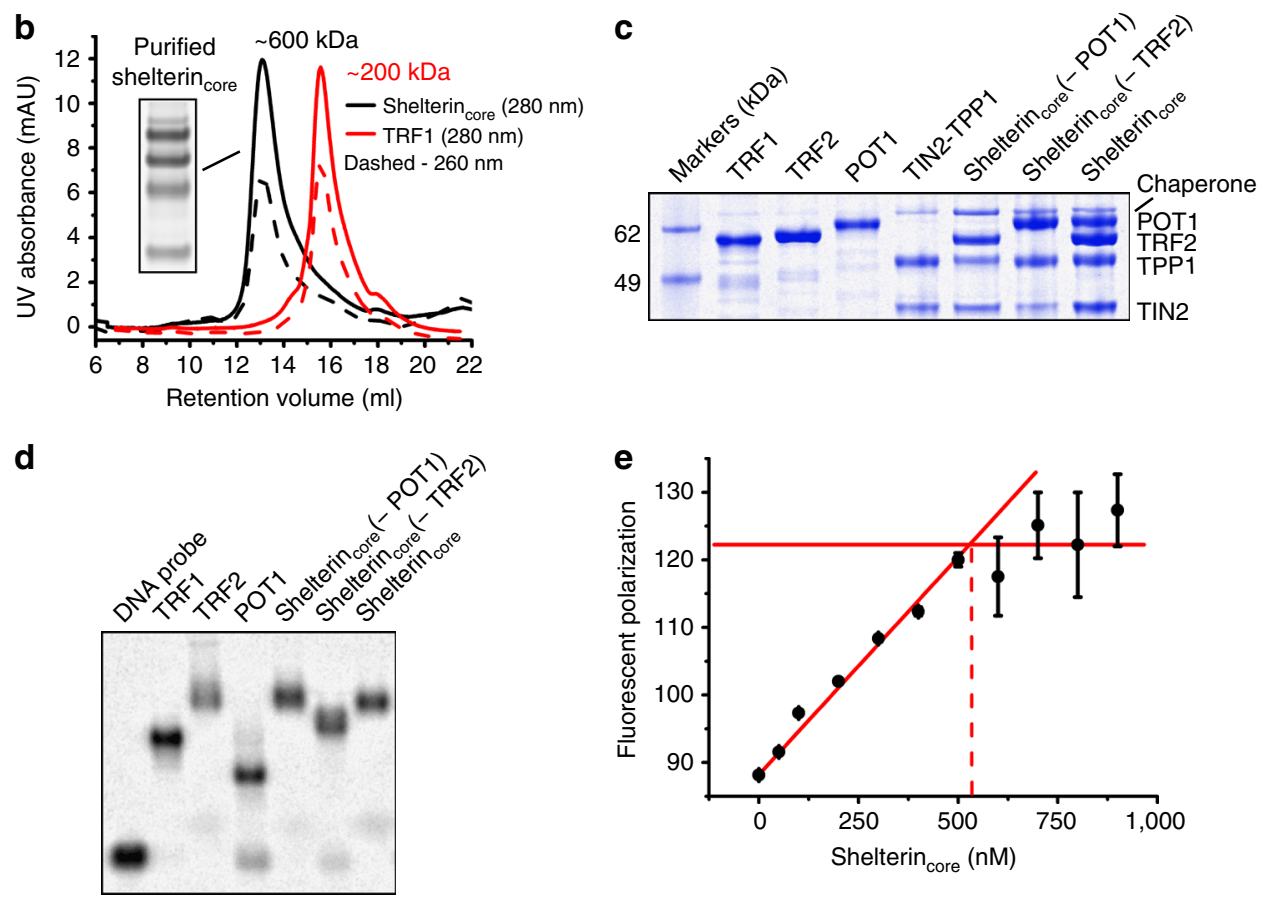

Fig. 1 Human shelterin proteins form stable protein and DNA-protein complexes in vitro. a Cartoon schematics of shelterin complexes reconstituted in this work. b Representative size-exclusion chromatography trace of purified shelterin ${ }_{\text {core }}$ complex using Superose $610 / 300$ increase column. The trace of TRF1 is included for comparison. c SDS-PAGE of purified recombinant human shelterin complexes expressed and reconstituted in Tni insect cells. Soluble purified individual shelterin subunits TRF1, TRF2, and POT1 are shown for comparison. The band above POT1 was identified via mass spectrometry to be the HSP70 chaperone. SDS-PAGE (sodium dodecyl sulfate-polyacrylamide gel electrophoresis) is visualized with Coomassie blue stain. $\mathbf{d}$ Agarose-EMSA shows stable protein-DNA complexes formed by recombinant human shelterin complexes containing TRF2, POT1, or both with ss/ds telomeric DNA substrate (C8). The telomeric ss/ds DNA substrate is ${ }^{32} \mathrm{P}-5^{\prime}$-labeled (longer strand) and incubated with $500 \mathrm{nM}$ protein for 30 min at room temperature before running on a $0.5 \%$ agarose gel. The experiments in $\mathbf{b}-\mathbf{d}$ were repeated twice (independent experiments) to ensure consistency. e Saturation-binding assay to determine shelterin ${ }_{\text {core }}$ complex DNA-binding activity. $500 \mathrm{nM}$ Alexa-488-5'-labeled C8 substrate was used in a fluorescent polarization assay with

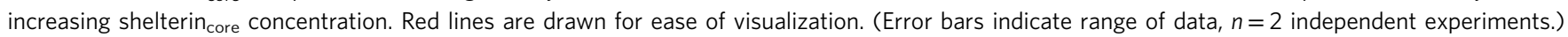


a

C8

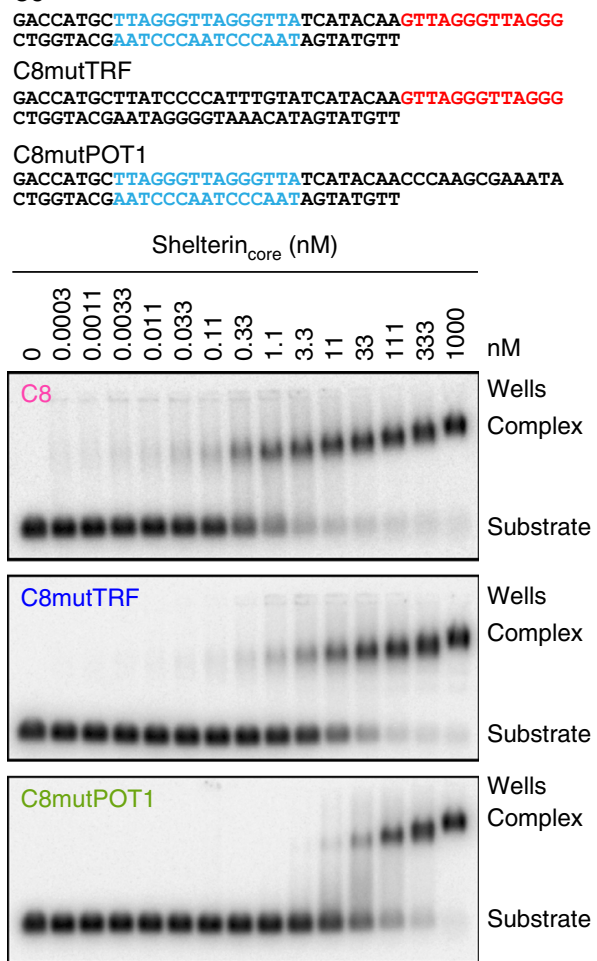

b
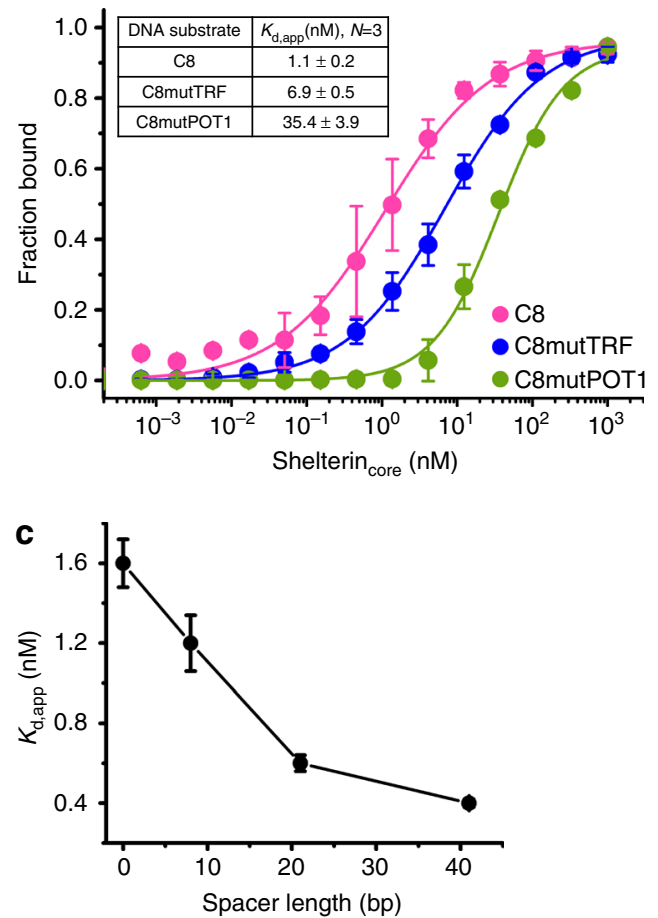

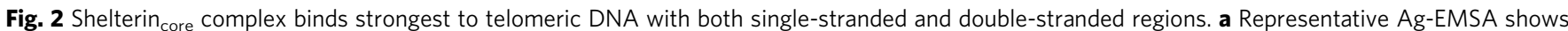
shelterin $_{\text {core }}$ complex binding to a telomeric DNA substrate (C8) with binding sites for both TRF2 dimer and POT1 and to C8mutTRF and C8mutPOT1, which have mutated TRF2 dimer and POT1-binding sites, respectively. $\mathbf{b}$ The equilibrium dissociation constants $\left(K_{\mathrm{d}, \text { app }}\right)$ were determined through curve fitting (with Hill equation) from the Ag-EMSA gels. Error bars represent s.d. ( $n=3$ independent experiments). c Binding affinity increases some what with increasing spacer length (base pairs) between TRF2 dimer and POT1-binding sites. (Error bars are s.d., $n=3$ independent experiments.)

addition to telomerase recruitment, TPP1 present in the TPP1-POT1 heterodimer has been shown to be a telomerase processivity factor in vitro ${ }^{28}$, and this is achieved by slowing telomerase dissociation from the DNA primer and aiding translocation $^{29}$.

Even though we know the overall shelterin protein composition of telomeres ${ }^{30}$, we know very little about the stoichiometry of different possible variations of shelterin complexes, their protein-protein and protein-DNA stability, and also how they are assembled and distributed along telomeres. Knowing this information will contribute to understanding how these protein complexes perform their functions in telomerase recruitment, regulation, and telomere protection. Individual shelterin proteins have been successfully purified from both bacterial ${ }^{21}, 31$ and insect $^{17,30}$ cells and provided valuable information on their functions. Until very recently, the only binary shelterin complex studied in pure form has been a heterodimer consisting of POT1 bound to an $\mathrm{N}$-terminal domain of TPP $1^{28}$. Although human/ mouse shelterin complexes immuno-purified from cell lysates have provided valuable insights regarding their composition, size, and DNA-binding properties ${ }^{7}, 8,13,32,33$, the low yield and heterogeneity of partially purified protein complexes limit quantitative studies.

Here, we expressed and purified various human shelterin complexes in sufficient quantity for both biochemical and biophysical characterization. We focused on TRF2-containing shelterin complexes rather than those containing TRF1, given the profound importance of TRF2 for telomere structure ${ }^{34}$. We show that most of the shelterin complexes can be purified without dissociation, indicating they form stable complexes at least in vitro. The shelterin complex that has both TRF2 and POT1 binds to single-stranded/double-stranded telomeric DNA junctions preferentially to exclusively single-stranded or doublestranded telomeric DNAs. We measured the stoichiometry of several shelterin complexes assemblies and revealed TRF2 and TIN2 have an unequal 2:1 (TRF2:TIN2) stoichiometry. We also identified a peptide region from TPP1 that is critical and sufficient to interact with TIN2-a key interaction for shelterin complex assembly. We further show TPP1 tethered to a telomere via TRF2-TIN2 or via POT1 is sufficient to confer its telomerase processivity function.

\section{Results}

Reconstituted human shelterin forms stable complexes. To express the various shelterin protein subunits and complexes, we used the insect cell/baculovirus system (Tni insect cells), which provides better machinery for folding mammalian proteins than bacterial systems. We co-expressed TRF2, TIN2, TPP1, and POT1 by simultaneous infection of cells with individual shelterin baculoviruses. We named the shelterin complex consisting of the four subunits (TRF2, TIN2, TPP1, and POT1) as the shelterin core complex, defined as the minimal shelterin complex capable of binding both single-stranded and double-stranded telomeric DNA (Fig. 1a). Shelterin complexes consisting of TRF2-TIN2-TPP1 and TIN2-TPP1-POT1 are named shelterin core $_{\text {(-POT1) and }}$ shelterin $_{\text {core }}(-\mathrm{TRF} 2)$, respectively, with reference to their loss of single-stranded or double-stranded telomeric-binding properties. All shelterin proteins and complexes were purified with a final size-exclusion chromatography (SEC) step and a single-peak 
a

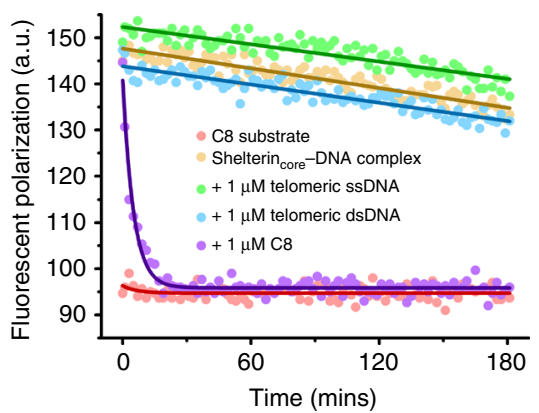

b

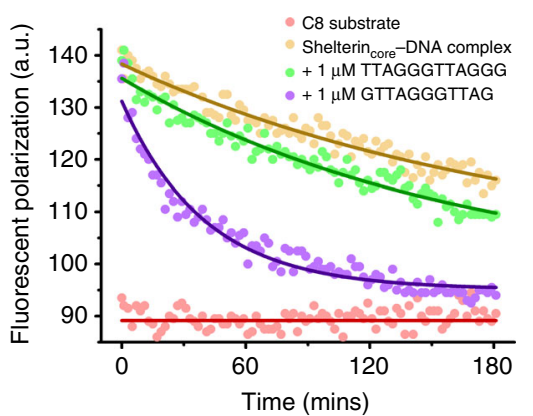

c

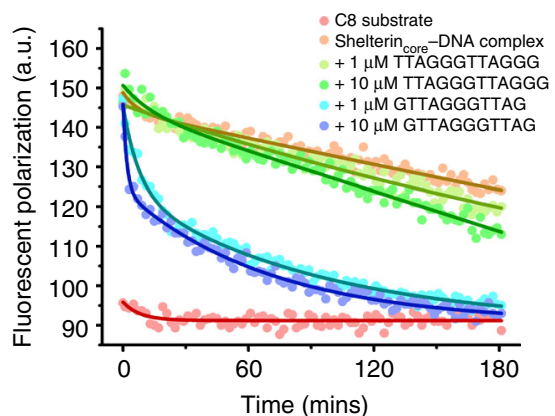

d

\begin{tabular}{|l|c|}
\hline \multicolumn{1}{|c|}{ Telomeric competitor } & Half-life $(\mathrm{min}), n=3$ \\
\hline Single-stranded (TTAGGG) ${ }_{2}$ & $>180$ \\
\hline Single-stranded GTTAGGGTTAG & $45.5 \pm 2.2$ \\
\hline Double-stranded (TTAGGG) ${ }_{2}$ TTA & $>180$ \\
\hline Single-/double-stranded junction (C8) & $5.1 \pm 0.3$ \\
\hline
\end{tabular}

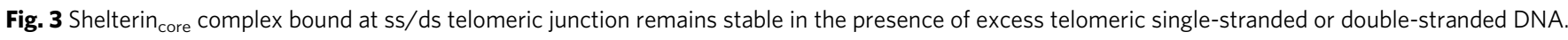

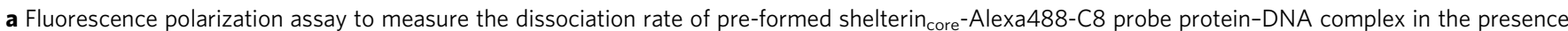
of excess single-stranded, double-stranded and ss/ds junction telomeric competitors. $5 \mathrm{nM}$ of Alexa488-C8 probe was incubated with $100 \mathrm{nM}$ of shelterin $_{\text {core }}$ complex for $30 \mathrm{~min}$ before adding $1 \mu \mathrm{M}$ competitor (200-fold excess to fluorescent probe). b Comparison of the complex dissociation rate with single-stranded telomeric competitors with either 3' TTAGGG or TTAG. c Comparison of dissociation rates of complexes with 1 and $10 \mu \mathrm{M}$ singlestranded telomeric DNA competitor. d Summary of complex dissociation rates in the presence of various telomeric competitors obtained from singleexponential decay function fitting. (Error bars are s.d., $n=3$ independent experiments using 2 different protein batches.)

corresponding to the protein/complex was then collected to ensure protein/complex homogeneity.

All four shelterin proteins-TRF2, TIN2, TPP1, and POT1elute in the same SEC peak (Fig. 1b), indicating the four proteins can form a stable shelterin core complex. Shelterin core $(-\mathrm{POT} 1)$ and shelterin $_{\text {core }}(-\mathrm{TRF} 2)$ complexes are also stable as reconstituted complexes expressed in insect cells. Figure 1c shows the SDSPAGE analysis of all purified shelterin proteins and stable complexes. To test the telomeric DNA binding of the purified shelterin protein complexes, we used a DNA substrate (annotated as C8) comprising both single-stranded and double-stranded telomeric regions separated by $8 \mathrm{bp}$ of random double-stranded DNA to ensure the strand hybridization register. All tested shelterin proteins and complexes bound the C8 DNA substrate in an Agarose-electrophoretic mobility shift assay (Ag-EMSA) (Fig. 1d). Other than TRF2 (with some upwards smearing), all shelterin protein-DNA complexes migrated into the gel as single bands.

We then quantified the DNA-binding activity of the purified shelterin $_{\text {core }}$ complex by performing a saturation-binding assay using fluorescence polarization. The $\mathrm{C} 8$ probe longer strand was 5 -labeled with Alexa-488 dye and its fluorescence polarization was measured with increasing shelterin core $_{\text {complex concentration }}$ (Fig. 1e). The fluorescence polarization signal (500 nM DNA) increased linearly with shelterin core $_{\text {concentration before leveling }}$ off at $\sim 540 \mathrm{nM}$ onwards, indicating the shelterin $_{\text {core: }}$ DNA stoichiometry is $1: 1$ and the protein complex is $\sim 90 \%$ active for DNA binding.

Shelterin $_{\text {core }}$ binds best to ss/ds telomeric DNA junction. In order for the TPP1-POT1 complex or POT1 to localize to telomere ends in vivo, the train of TRF2-TIN2-TPP1-POT1 is required $^{35}, 36$. We tested if such an interaction could be recapi-

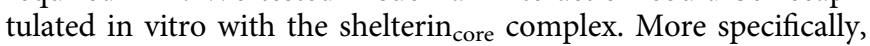
would the combination of TRF2 and POT1 binding to double- stranded and single-stranded telomeric DNA, respectively, enhance shelterin complex affinity at telomere ends?

To delineate the contributions of TRF2 and POT1 DNAbinding in the context of a protein complex, we mutated the TRF2 and POT1-binding sites of the C8 DNA substrate to generate C8mutTRF (does not bind TRF2) and C8mutPOT1 (does not bind POT1) substrates. Figure 2a shows representative Ag-EMSA gels of the three DNA substrates with increasing shelterin $_{\text {core }}$ complex concentration. C8 has an equilibrium dissociation constant $\left(K_{\mathrm{d}}\right)$ of $1.1 \pm 0.2 \mathrm{nM}$ (Fig. 2b). C8mutTRF, which has a mutated TRF2-binding site, has $K_{\mathrm{d}}=6.9 \pm 0.5 \mathrm{nM}$ while C8mutPOT1, which has a mutated POT1-binding site, has $K_{\mathrm{d}}=35.4 \pm 3.9 \mathrm{nM}$. Removal of POT1 from shelterin core $_{\text {reduced }}$ its affinity for the C8 DNA by $\sim 14$-fold, and removal of TRF2 had an even larger effect (Supplementary Fig. 1). The binding of shelterin complexes to purely single-stranded or double-stranded telomeric DNA was also measured and, as expected, complexes containing POT1 bound telomeric ssDNA and those containing TRF2 bound telomeric dsDNA (Supplementary Fig. 2). All interactions showed substantial specificity for telomeric DNA sequence, although binding to non-telomeric DNA could be observed in the micro-molar concentration range (Supplementary Fig. 2). As a cautionary note, initial unoptimized protein preparations of shelterin core (-POT1) showed strong binding to telomeric single-stranded DNA which disappeared when the expression protocol was optimized. Overall, these experiments revealed the contributions of both TRF2 and POT1 to DNAbinding by the shelterin complex and sub-complexes.

To determine if the distance between the TRF2 and POT1-

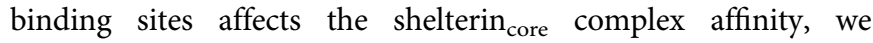
measured the binding to telomeric ss/ds substrates in which these sites were separated by spacers of $0,8,21$, and $41 \mathrm{bp}$. We found that all of these DNA substrates formed high-affinity complexes; the shelterin core $_{\text {complex }} K_{\mathrm{d}}$ progressively became stronger with increasing spacer length, with 41 bp spacer having a $K_{\mathrm{d}}$ of $\sim 0.5 \mathrm{nM}$ (Fig. 2c). Taken together, we demonstrate that 


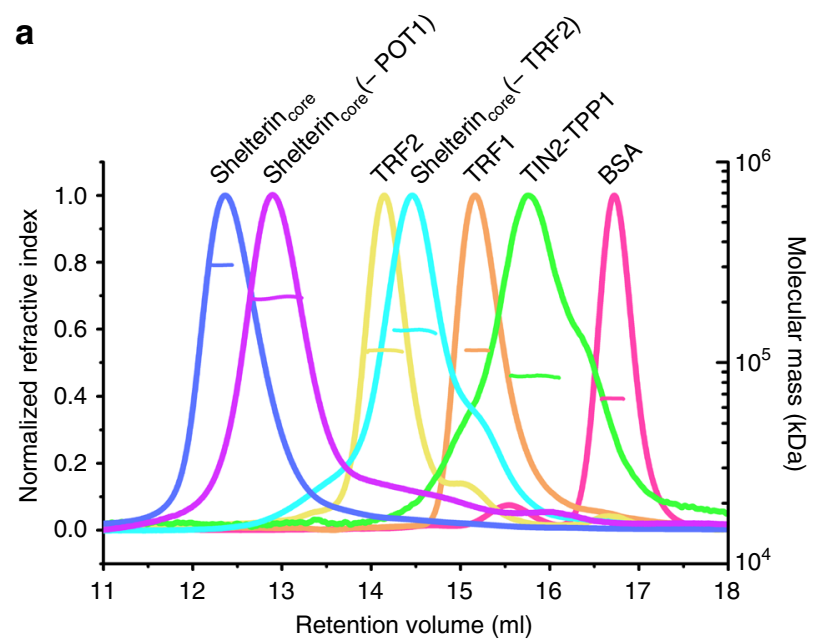

C

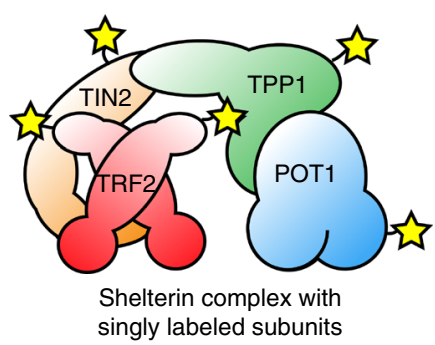

d

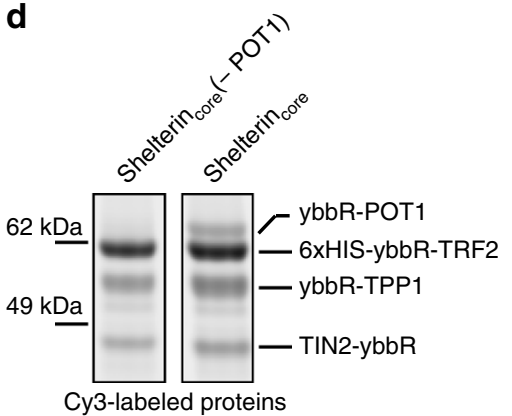

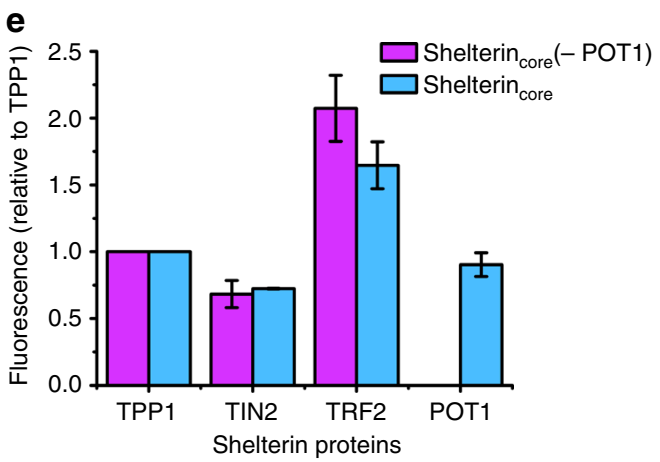

Fig. 4 Human shelterin complexes have a 2:1 TRF2:TIN2 stoichiometry. a Size-exclusion chromatography multi-angle light scattering (SEC-MALS) assay to determine absolute molecular mass of various purified human shelterin complexes. b Summary of the shelterin complexes molecular mass (percentage error from software fitting) and the expected molecular stoichiometry. c Shelterin complexes were expressed with a single ybbR tag for each subunit. $\mathbf{d}$ The purified complexes were labeled with fluorescent dye (Cy3) for relative stoichiometry analysis in a SDS-PAGE gel by band fluorescence-intensity measurement. e The quantified fluorescence intensities were normalized to TPP1 counts and compared. (Error bars represent the range of data, $n=2$ independent experiments using different protein batches.)

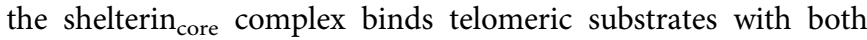
single-stranded and double-stranded regions (i.e., ss/ds telomere junction) more strongly than substrates with just either singlestranded or double-stranded telomeric DNA.

Pre-bound shelterin core $_{\text {prefers }} 3^{\prime}$ TTAGG telomeric ssDNA. The human double-stranded telomeric region is on the order of several $\mathrm{kb}^{37}$ and thus it is in excess of the single-stranded region which is only several hundred $\mathrm{nt}^{38}$. This could potentially lead to sequestration of shelterin complexes away from the $3^{\prime}$ telomeric overhangs and cause telomere dysfunction. To determine if excess telomeric DNA substrates can compete the shelterin core $_{\text {complex }}$ from ss/ds telomeric DNA, we measured the stability of the shelterin $_{\text {core }}$-C8 protein-DNA complex in the presence of excess single-stranded or double-stranded telomeric DNA using the fluorescence polarization assay. The shelterin core $_{\text {complex dis- }}$ sociated rapidly with a half-life of $5.1 \pm 0.3 \mathrm{~min}$ from the labeled C8 DNA substrate when competed with excess C8 substrate, while it remained relatively stable when competed with either excess single-stranded (TTAGGG) 2 or double-stranded (TTAGGG) $)_{2}$ TTA DNA substrates (Fig. 3a). This suggests that

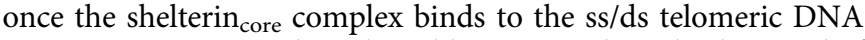
junction, it remains relatively stable against a large background of double-stranded telomeric DNA; this would effectively target TPP1 and POT1 to the chromosome $3^{\prime}$ ends.
The high affinity and stability of shelterin core $_{\text {at }}$ ss/ds telomeric junction could also prevent TPP1-POT1 or POT1 from binding to the $3^{\prime}$ end of the single-stranded telomeric tail, which would be a deleterious outcome. We therefore tested the stability of the shelterin $_{\text {core }}-\mathrm{C} 8$ complex in the presence of single-stranded telomeric DNA ending with TTAG, which is the preferred human telomere overhang sequence ${ }^{39}$. We saw shelterin core $_{\text {co }}$ complex was effectively competed off C8 with excess GTTAGGGTTAG substrate with a half-life of $45.5 \pm 2.2 \mathrm{~min}$ (Fig. 3b). Increasing the single-stranded telomeric DNA competitor concentration 10 -fold did not change the half-life significantly (Fig. 3c), indicating that the competitor DNA traps the protein upon dissociation rather than actively attacking the protein-DNA complex. A table summarizing the half-lives is shown in Fig. 3d. From the above, there is clearly a strong preference among various DNAs concerning their ability to

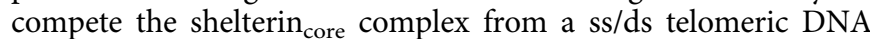
junction: ss/ds junction > TTAG-ending ssDNA > TTAGGG ss or ds DNA.

Human shelterin $_{\text {core }}$ has unequal 2:1 TRF2:TIN2 stoichiometry. The stoichiometry of shelterin complexes is fundamental in building working models to understand how shelterin proteins are recruited and assembled at telomeres. The global stoichiometry of shelterin proteins at telomeres in cultured cells has been studied $^{30}$ but does not address the stoichiometry of subunits 
a

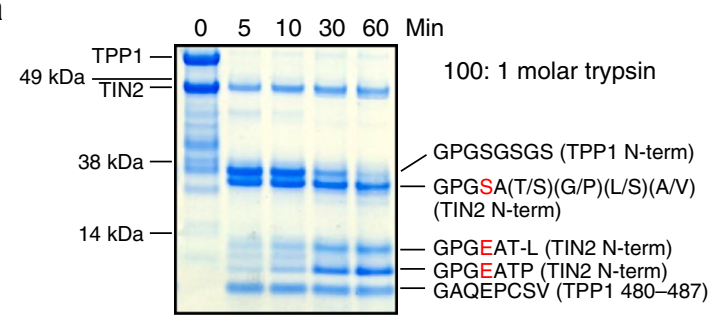

b

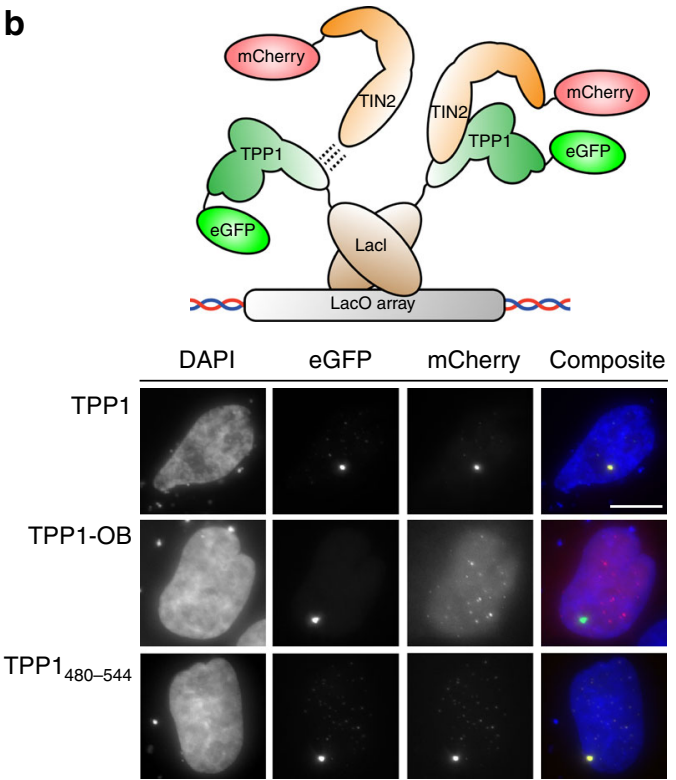

d

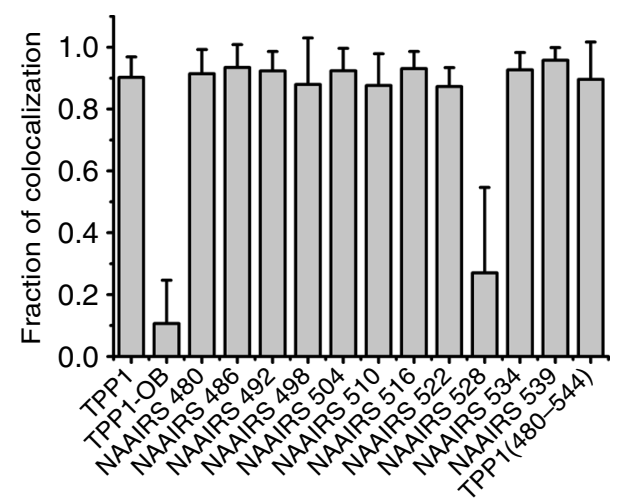

e

\begin{tabular}{|c|c|c|c|}
\hline $\begin{array}{l}\text { MBP-TIN2 } \\
\text { only }\end{array}$ & + wt TPP1 & $\begin{array}{c}+ \text { NAAIRS } \\
492\end{array}$ & $\begin{array}{c}\text { + NAAIRS } \\
528\end{array}$ \\
\hline$\overline{\text { Input Elute }}$ & $\overline{\text { Input Elute }}$ & $\overline{\text { Input Elute }}$ & Input Elute \\
\hline$E$ & 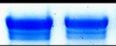 & 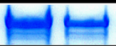 & $=$ \\
\hline
\end{tabular}

C

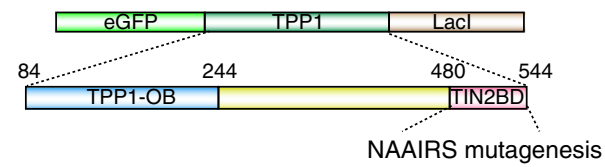

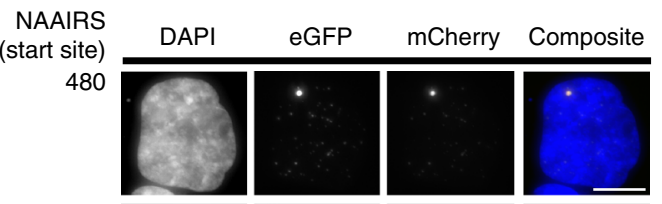

486
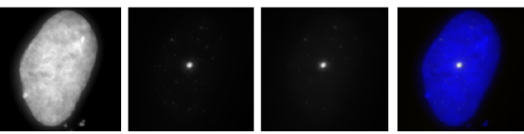

492
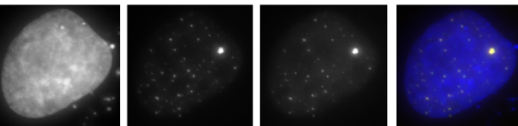

498
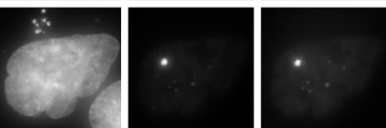

504
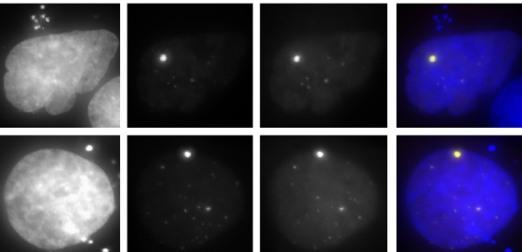

510
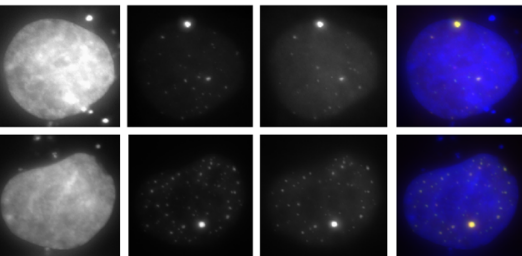

516
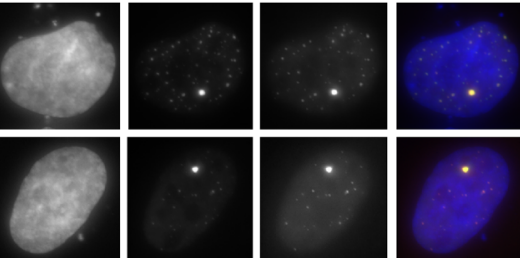

522
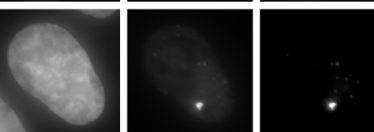

528
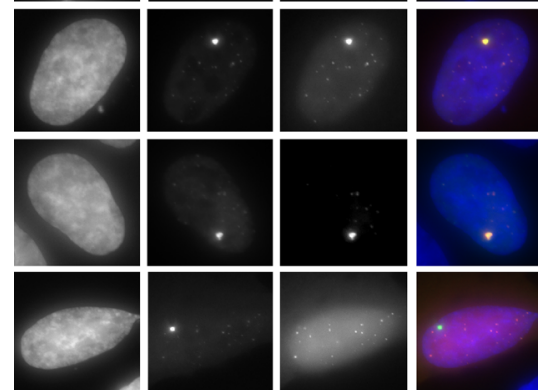

534
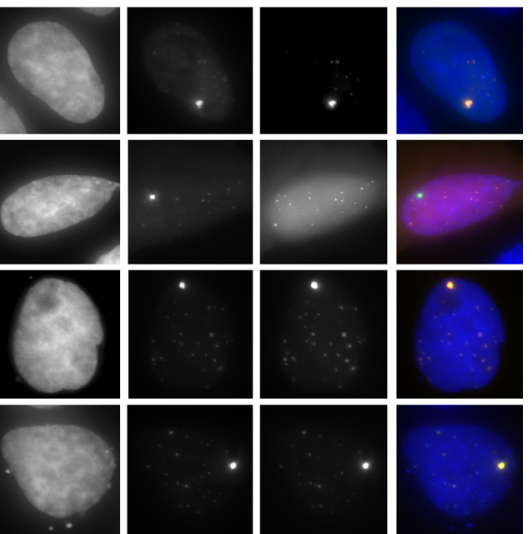

539
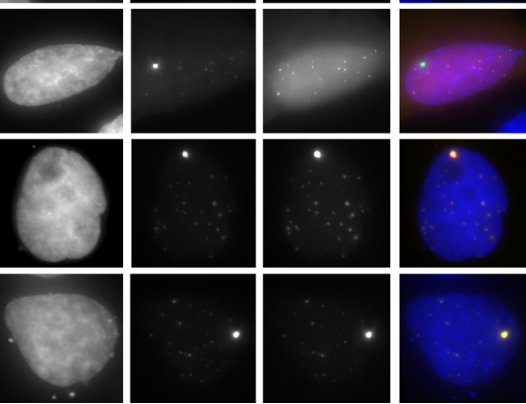

Fig. 5 Identification of a TPP1 region critical and sufficient for TIN2 interaction. a Trypsin limited proteolysis of TIN2-TPP1 complex and peptide sequencing. Red letters in the peptide sequence denote mismatch to the wild-type TPP1 sequence. $\mathbf{b}$ Cartoon schematic showing the Lacl-LacO array system used to test the TIN2-TPP1 interaction via fluorescence colocalization in U2-OS cells. Positive control shows full-length TPP1 (eGFP) co-localizing with TIN2 (mCherry). Negative control consisting of TPP1 OB-fold with the TIN2-interacting domain deleted (eGFP) shows multiple TIN2 spots (mCherry) that do not colocalize. Sufficiency for TPP1 (480-544) peptide to interact with TIN2 is also shown. Scale bar is $10 \mu \mathrm{m}$. c Top, schematic of TPP1 Lacl construct region used for NAAIRS mutagenesis. Bottom, representative fluorescent images of nuclei from transfected cells. Asterisk points to the NAAIRS mutant that has the lowest fraction of colocalization (defined as colocalization of mCherry with a single GFP focus in a single nucleus). Scale bar is $10 \mu \mathrm{m}$. $\mathbf{d}$ Quantification of the fraction of colocalization between eGFP-TPP1 constructs and mCherry-TIN2 (Error bars are s.d., $n>50$ nuclei per construct from 3 biological replicates). e Streptavidin-coated beads with biotinylated TPP1 480-544 peptide were used to capture MBP-TIN2. The amount of captured MBP-TIN2 is shown in the elute lanes. MBP-TIN2 captured by biotinylated TPP1 480-544 peptide with NAAIRS mutations at positions 492 (positive control) and 528 (affected region) are compared with the wild-type peptide. (Two independent experiments gave equivalent results.) 
a

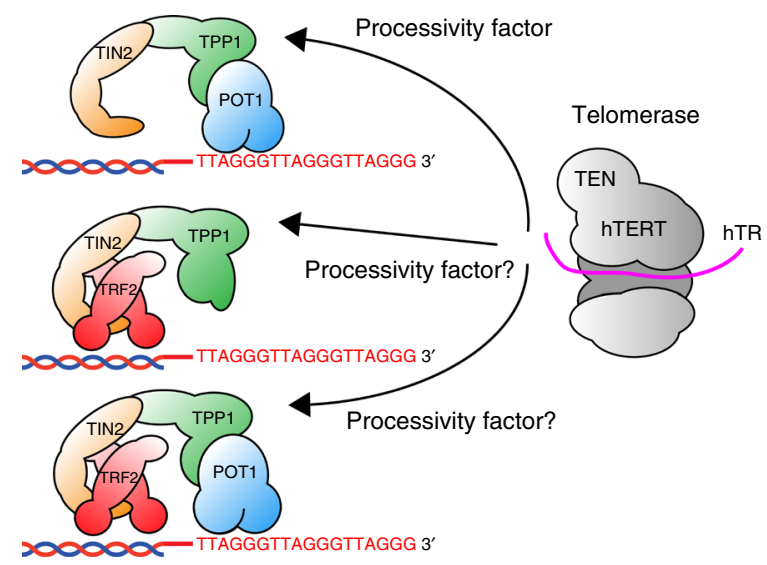

Telomerase primer (C8a)

GACCATGCTTAGGGTTAGGGTTATCATACAATTAGGGTTAGGGTTAGGG CTGGTACGAATCCCAATCCCAATAGTATGTT
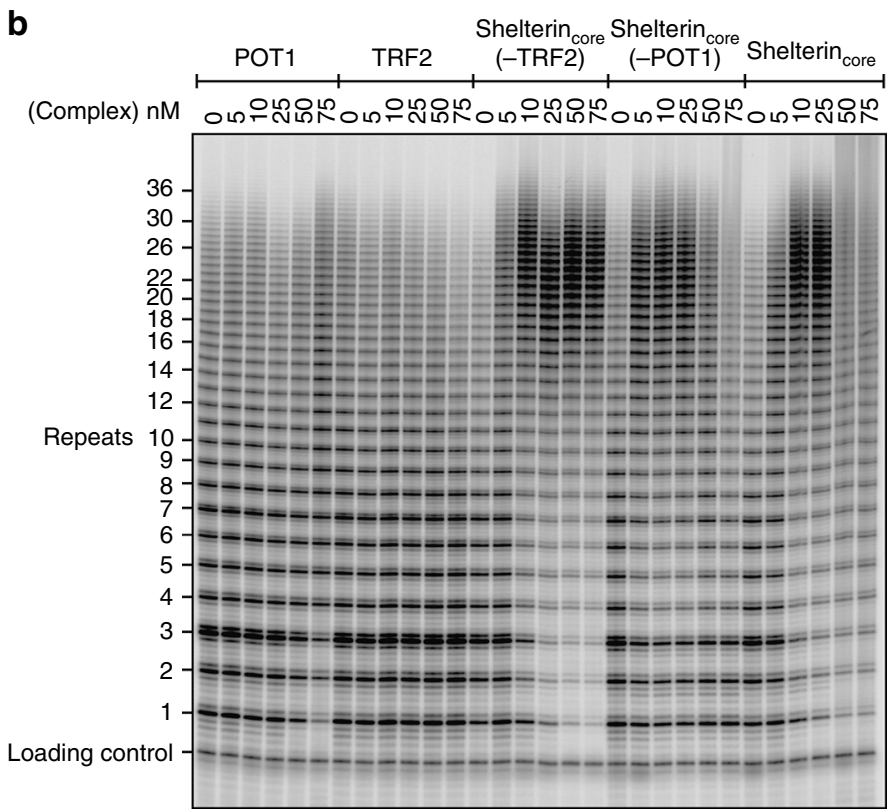

C

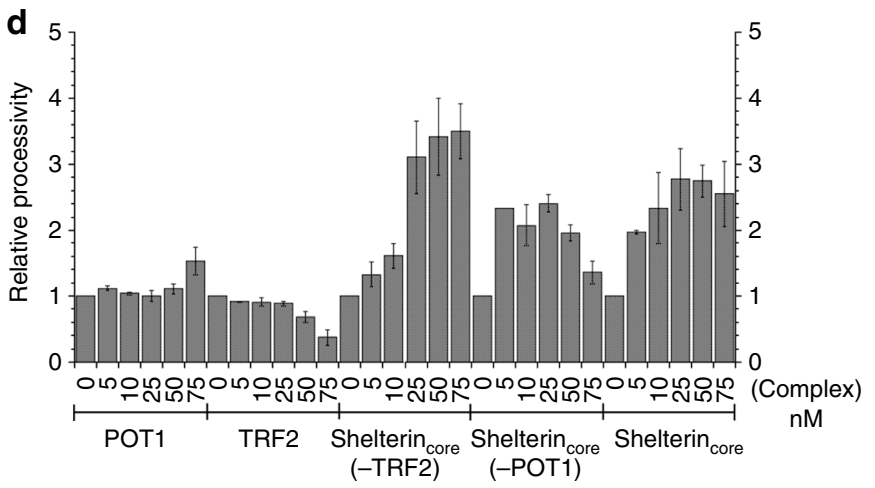

Fig. 6 TPP1 tethering is sufficient for shelterin enhancement of telomerase processivity. a Cartoon schematics of the shelterin complexes tested and the primer used (C8a), which allows binding of TRF2, POT1 and telomerase. b Direct telomerase assay to determine the effects of shelterin complexes on telomerase activity and processivity. c Total activity of telomerase primer elongation products (normalized to a radioactive oligonucleotide loading control) with bound shelterin protein complexes at various concentrations (nM). d Telomerase processivity with each shelterin protein/complex. The processivity (relative to no-protein lane, which is normalized to 1) was calculated by dividing the counts $>14$ repeats by total counts. (Error bars in panels $\mathbf{c}$ and $\mathbf{d}$ indicate the range for two independent experiments.)

within an individual shelterin complex. Here we used the SEC multi-angle light scattering (SEC-MALS) technique to measure the absolute mass of our purified shelterin proteins and complexes (Fig. 4a). The TRF1 measured mass is $115.1 \mathrm{kDa}$, which is closest to a predicted dimer mass of $108 \mathrm{kDa}$ (Fig. 4b). Similarly, for TRF2, we obtained a mass of $114.9 \mathrm{kDa}$, which is closest to a dimer mass of $119 \mathrm{kDa}$. A dimeric state of TRF1 and TRF2 is consistent with previous literature ${ }^{9,} 11$. For TIN2-TPP1, we measured the mass to be $85.9 \mathrm{kDa}$, which is closest to a $1: 1$ heterodimer mass of $89 \mathrm{kDa}$. For shelterin $_{\text {core }}(-\mathrm{TRF} 2)$ complex, we measured the mass to be $144.6 \mathrm{kDa}$, which is closest to a $1: 1: 1$ heterotrimer mass of $162 \mathrm{kDa}$.

Given that TRF2 is a dimer, one might expect each monomer to bind a TIN2 molecule, which would give a 2:2:2 stoichiometry of TRF2:TIN2:TPP1 or 2:2:2:2 stoichiometry of TRF2:TIN2: TPP1:POT1. However, by SEC-MALS the shelterin core $_{\text {(-POT1) }}$

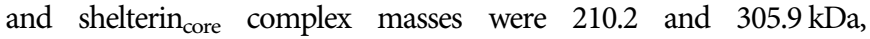
respectively. The closest stoichiometry match for $\operatorname{shelterin}_{\text {core }}(-\mathrm{POT} 1)$ would be 2:1:1 (TRF2:TIN2:TPP1) which gives an expected mass of $211 \mathrm{kDa}$, while for shelterin ${ }_{\text {core, }}$ the closest match is $2: 1: 1: 1$
(TRF2:TIN2:TPP1:POT1) which gives an expected mass of $282 \mathrm{kDa}$, or 2:2:1:1 which gives an expected mass of $321 \mathrm{kDa}$. To differentiate these two possibilities for shelterin core $_{\text {complex }}$ stoichiometry and also to confirm shelterin core $_{\text {(-POT1) complex }}$ stoichiometry, we added an N-terminal ybbR $\operatorname{tag}^{40}$ to each shelterin protein. The tags did not interfere with complex assembly. We then fluorescently labeled the purified ybbRtagged shelterin ${ }_{\text {core }}\left(-\right.$ POT1) and shelterin core $_{\text {complexes, and }}$ quantified the fluorescence intensities from SDS-PAGE (Fig. 4c-e). The TRF2 band had almost twice as much fluorescent signal as the TIN2, TPP1, and POT1 bands (Fig. 4e). Thus, using two separate techniques, we show the TRF2:TIN2 stoichiometry to be an unequal 2:1 in the context of shelterin complexes. This is unexpected since it has been shown that a TRF2 monomer binds one TIN2 peptide (also shown vice versa) ${ }^{14}$ thereby predicting an equal stoichiometry of these subunits in the shelterin $_{\text {core }}$ complex.

TPP1 $1_{480-544}$ is critical and sufficient for TIN2 interaction. The TIN2-TPP1 interaction is known to be critical for higher-order 
shelterin complex assembly ${ }^{7}$. It is thus important to identify the regions of TIN2 and TPP1 that are involved in this interaction. Although deletion studies have identified regions of

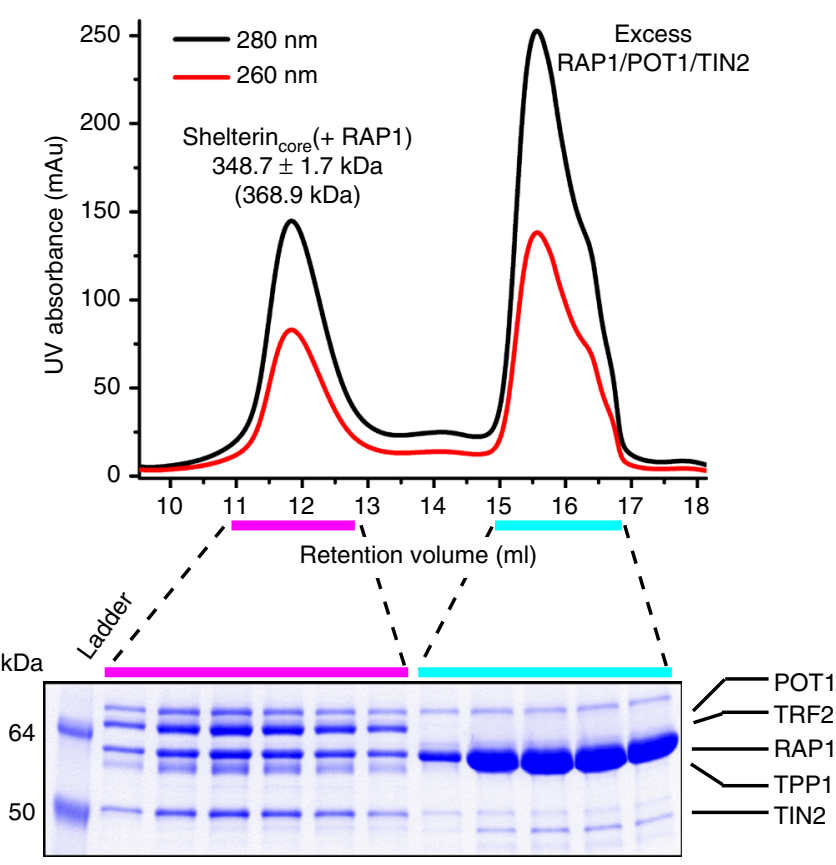

TIN2 and TPP1 that are critical for their interaction ${ }^{7}, 19,41$, our purified complexes gave us the opportunity to elucidate a specific interaction patch on TPP1 and TIN2. The purified
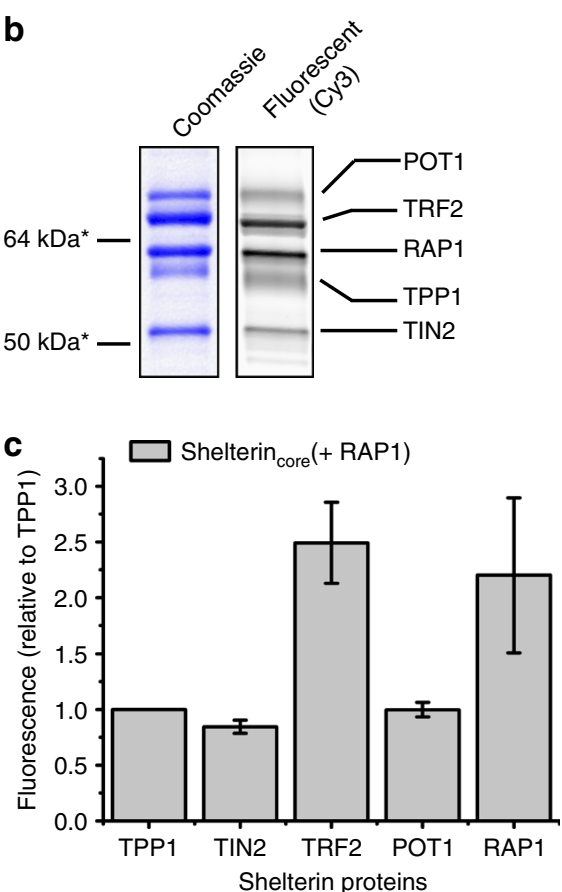

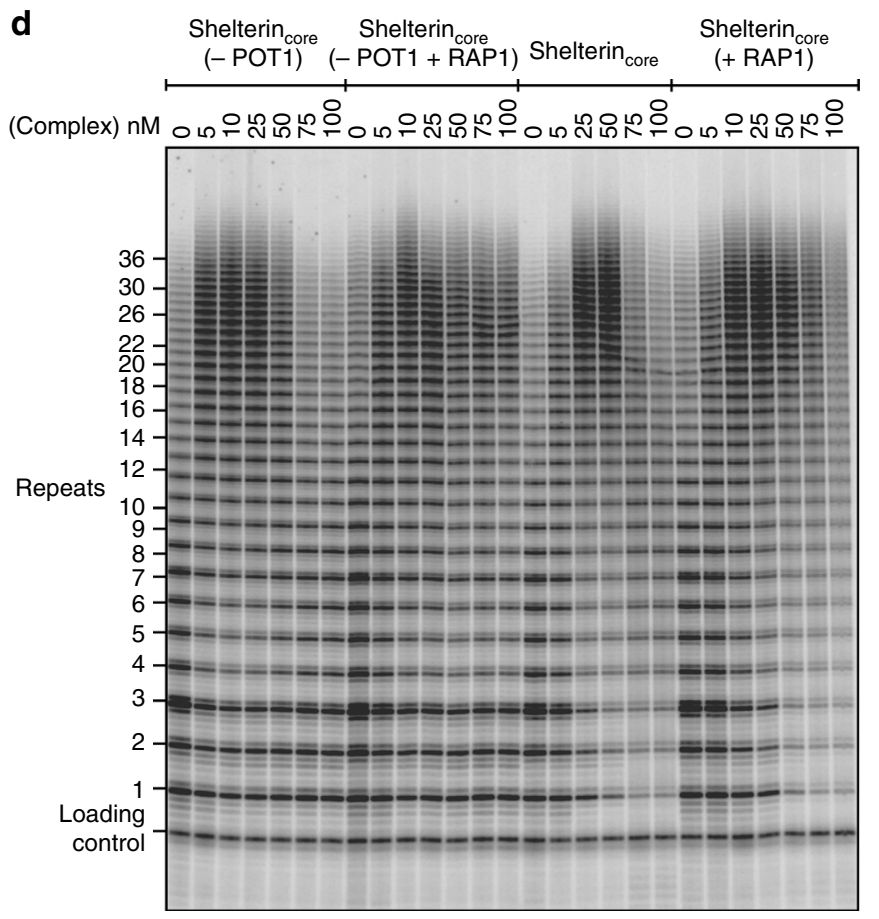

e
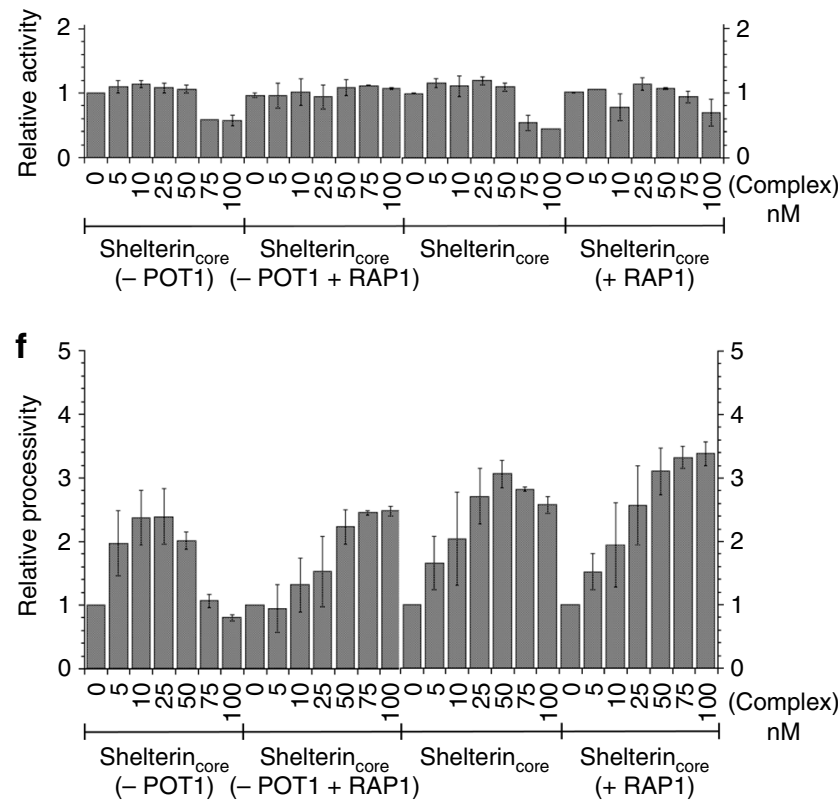

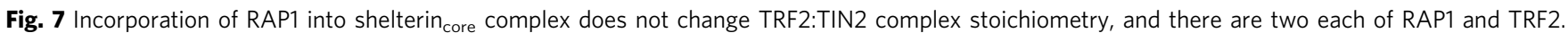
Telomerase stimulation by shelterin complexes is also not affected by RAP1 inclusion. a Superose 6 gel-filtration trace of co-expressed shelterin core (+RAP1) complex (RAP1-TRF2-TIN2-TPP1-POT1) showed a mono-disperse peak (left peak) with SDS-PAGE showing five distinct Coomassie-stained bands representing the five shelterin proteins. SEC-MALS analysis determined the protein complex to be $348.7 \pm 1.7 \mathrm{kDa}$, with the bottom number in parentheses being the theoretical mass for a 2:2:1:1:1 (RAP1:TRF2:TIN2:TPP1:POT1) complex. The right peak is composed of excess un-incorporated RAP1,

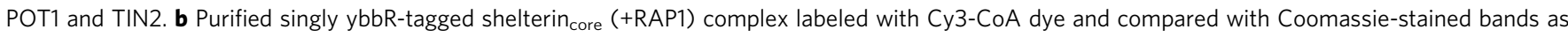
reference. * Molecular weight is an apparent value of SeeBlue Plus2 protein marker (Thermo Fisher) on a tris-glycine gel. c Quantification of fluorescenceintensity showed TRF2:TIN2 relative stoichiometry to be 2:1 $(P<0.05)$ while TRF2:RAP1 is 1:1. Error bars indicate s.d. for three independent experiments performed with three different protein preparations. d Direct telomerase assay to determine the effects of RAP1 inclusion on processivity stimulation by shelterin $_{\text {core }}(-\mathrm{POT1})$ or shelterin core $_{\text {complexes. }}$ Total activity of telomerase primer elongation products (relative to no-protein lane) with bound shelterin protein complexes at various concentrations $(n M)$. $\mathbf{f}$ Telomerase processivity (relative to no-protein lane) with each shelterin protein/complex. (For panels e and $\mathbf{f}$, error bars indicate the range for two independent experiments.) 
TIN2-TPP1 complex was subjected to limited proteolysis (Fig. 5a). N-terminal sequencing of the protected peptides revealed they were from the TIN2 N-terminus, the TPP1 N-terminus, and TPP1(480-487). MALDI further revealed the molecular mass of the TPP1(480-487) protected peptide to be $10.25 \mathrm{kDa}$, which indicates it to be TPP $1_{480-544}$ including the $3 \times$ FLAG at the C-terminus. TPP $1_{480-544}$ is 65 aa long and is consistent with having the C-terminal 22 aa that was previously identified to be critical for TIN2 interaction ${ }^{19}$. We did not obtain reliable mass for the other protected peptides from TIN2.

To identify region(s) within $\mathrm{TPP} 1_{480-544}$ that are critical for TIN2 interaction, we used the LacI-LacO array system ${ }^{26,27}$ to test TIN2-TPP1 interaction in cells upon TPP1 $1_{480-544}$ NAAIRS mutagenesis $^{42}$. The TPP1 domain was inserted between enhanced-GFP (eGFP) and LacI (Fig. 5b). The TPP1 constructs were co-expressed with mCherry-tagged TIN2 in the U2OS 2-6-3 cell line, which has a $\mathrm{LacO}$ array integrated in its chromosome $1^{43}$. Colocalization of the eGFP (green channel) and mCherry (red channel) at the single-LacO site would indicate interaction between TIN2 and TPP1. eGFP-TPP1-LacI was used as the positive control while eGFP-TPP1-OB-LacI was used as the negative control (Fig. 5b). TPP1 colocalized with TIN2 at $90 \%$ of the LacO sites while TPP1-OB, which does not interact with TIN2, colocalized at $\sim 10 \%$ (Fig. $5 \mathrm{~d}$ ). We also tested the sufficiency of TPP1 $1_{(480-544)}$ peptide to interact with TIN2 and showed $\sim 90 \%$ colocalization between $\mathrm{TPP}_{(480-544)}$ and TIN2 (Fig. 5b, d). All TPP1 NAAIRS mutants except TPP1 $1_{\text {NAAIRS(528-533) }}$ colocalized with TIN2 at a level comparable to that of wild-type TPP1 (Fig. 5 c). TPP $1_{\text {NAAIRS(528-533) }}$ colocalized with TIN2 at only $25 \%$ of the LacO sites (Fig. 5d).

To further test if mutation at TPP1(528-533) disrupts the TIN2-TPP1 interaction, we performed a pull-down of maltosebinding protein (MBP)-TIN2 with resin-bound wild-type and mutant TPP1 $1_{480-544}$ peptides. Wild-type and NAAIRS 492 peptides could pull-down MBP-TIN2 while NAAIRS 528 peptide pulled down substantially less MBP-TIN2 (Fig. 5e). In addition to confirming that the NAAIRS mutation at TPP1(528-533) can disrupt the TIN2-TPP1 interaction, these data also show that the TPP $1_{480-544}$ peptide is sufficient for TIN2-TPP1 interaction.

Tethering of TPP1 is sufficient for telomerase stimulation. When TPP1-POT1 was identified as a telomerase processivity factor $^{28,31}$, TPP1 was recruited to the DNA substrate via its dimerization with POT1. However, POT1 is not required for telomerase recruitment to telomeres in vivo, where instead TIN2 recruits TPP $1{ }^{15}$. This suggests TPP1-POT1 may not be the major or only processivity factor for telomerase, and a shelterin complex

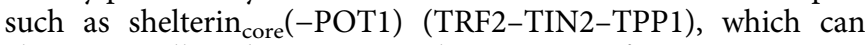
also potentially tether TPP1 to telomeres, may function as a more biologically relevant processivity factor for telomerase. To test this, we performed direct telomerase assays using shelterin cor- $_{\text {- }}$ e(-TRF2), shelterincore $(-P O T 1)$ and shelterin core complexes. These protein complexes were tested at increasing concentrations to ensure complete binding to the DNA. The telomerase primer used, C8a, contains a double-stranded telomeric region for TRF2 binding and a single-stranded region for telomerase and POT1 binding (Fig. 6a). In vivo reconstituted human core telomerase (hTERT and hTR) was immuno-purified from HEK293T cells.

Addition of POT1 or TRF2 alone to the telomerase extension reaction had only small effects on telomerase activity and processivity (Fig. 6b-d), consistent with previous studies ${ }^{28}, 44,45$.

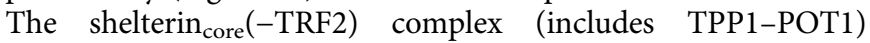
increased the processivity of human telomerase $\sim 3$-fold (Fig. $6 \mathrm{~d}$ ), which is consistent with a previous TPP1-POT1 study ${ }^{5}$. Similarly, shelterin $_{\text {core }}(-\mathrm{POT} 1)$ and shelterin ${ }_{\text {core }}$ also increased the telomerase product size distribution (Fig. 6b). Both shelterin core $_{\text {(-POT1) }}$ and shelterin core $_{\text {increased the telomerase processivity } \sim 2-3 \text {-fold }}$ (Fig. 6d). Total telomerase activity did not change with the addition of shelterin proteins/complexes (Fig. 6c). In addition, in the absence of a TRF2-binding site, shelterin core $_{\text {(-POT1) }}$ stimulated processivity only to a small extent (Supplementary Figs. 3 and 4) similar to that of TPP1-N alone ${ }^{28}$, indicating TRF2 ds telomeric DNA-binding to be a major factor for the observed telomerase stimulation by $\operatorname{shelterin}_{\text {core }}(-\mathrm{POT} 1)$. Overall, the above results demonstrate that the TPP1-POT1 heterodimer complex is not exclusive in stimulating telomerase processivity, and shelterin $_{\text {core }}(-\mathrm{POT} 1)$ can serve the same function with equivalent efficiency in vitro.

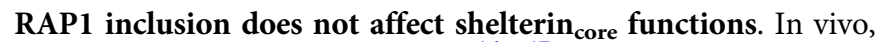
TRF2 is complexed with RAP1 ${ }^{46,47}$, and this complex is important in protecting telomeres from inappropriate homologydirected repair ${ }^{48}$. Having determined the shelterin $_{\text {core }}$ complex stoichiometry, a major question is if incorporation of RAP1 into the complex changes the complex stoichiometry of TRF2-TIN2, especially since RAP1 interacts at a TRF2 region near TRF2's TIN2-binding site ${ }^{22}$. To answer this question, we purified the shelterin $_{\text {core }}$ (+RAP1) complex (RAP1, TRF2, TIN2, TPP1, and POT1) to high homogeneity (Fig. 7a). SEC-MALS analysis determined the complex mass to be $\sim 350 \mathrm{kDa}$, which is between $322.2 \mathrm{kDa}\left(\right.$ shelterin $\left._{\text {core }}+1 \mathrm{RAP} 1\right)$ and $368.9 \mathrm{kDa}\left(\operatorname{shelterin}_{\text {core }}+\right.$ 2 RAP1) (Supplementary Fig. 5). To differentiate between these two possible stoichiometries, every subunit was singly tagged with ybbR (Fig. 7b). Quantification showed the 2:1 TRF2:TIN2 complex stoichiometry was not changed and TRF2:RAP1 had a 1:1 (2:2 in a complex) stoichiometry (Fig. 7c). In addition, using SEC-MALS, we found that our preparations of RAP1 alone behaved as a monomer in solution (Supplementary Fig. 5), contrary to the tetramer reported previously ${ }^{49}$.

In terms of DNA interactions, we found shelterin core $(-\mathrm{POT} 1$ + RAP1) complex had no significant changes in DNA-binding

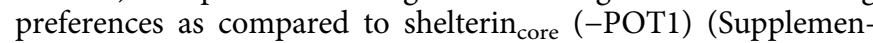
tary Fig. 6a). Similar results were obtained for shelterin core

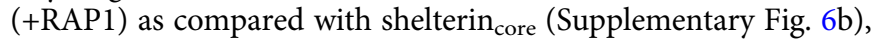
indicating RAP1 incorporation in human shelterin complexes has no significant impact on TRF2 and POT1 DNA-binding properties. Next, we asked if telomerase stimulation by RAP1-less shelterin complexes are affected by RAP1 inclusion. We found that shelterin $_{\text {core }}(-\mathrm{POT} 1+\mathrm{RAP} 1)$ and shelterin core $_{\text {(+RAP1) still }}$ stimulate telomerase processivity (Fig. 7d). Quantification confirmed that RAP1 inclusion did not affect telomerase activity (Fig. 7e). Maximal processivity stimulation was the same for all four complexes ( 2.5-3 fold) although the RAP1 complexes were able to sustain processivity stimulation at higher protein concentrations more effectively than complexes without RAP1 (Fig. 7f). Overall, we show RAP1 incorporation has no effect on human shelterin core $_{\text {complex stoichiometry and has minimal }}$ effects on telomeric DNA-binding and telomerase stimulation.

\section{Discussion}

Our finding that various forms of human shelterin can be expressed and purified as discrete protein complexes has provided much new biophysical information, such as the equilibrium binding constants of these complexes for telomeric ds and ss DNA substrates. This information is in general agreement with that recently reported for mouse shelterin containing the POT1a subunit $^{32}$. In addition, our work has provided molecular-level insight regarding three biological questions about shelterin: (1) How can POT1-TPP1 find the telomere $3^{\prime}$ end, given that 

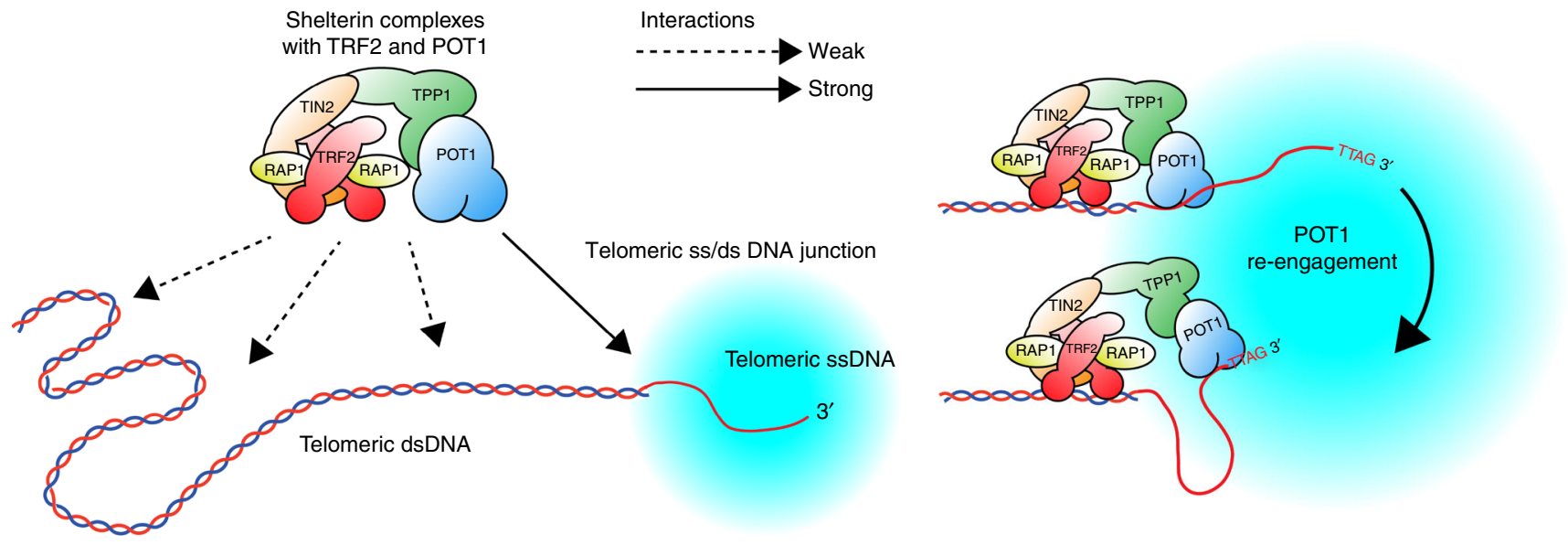

b Telomerase recruitment model

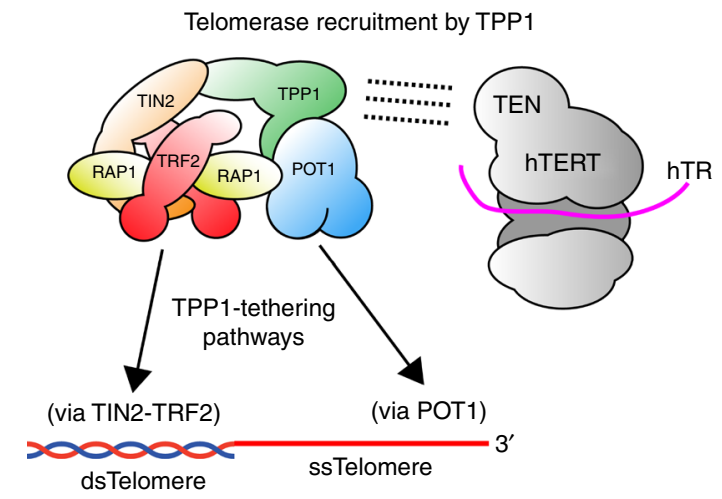

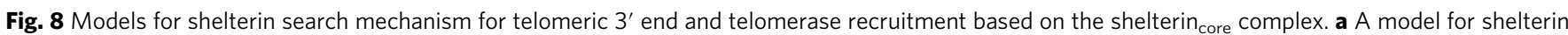
positioning at the telomeric $3^{\prime}$ end suggests a shelterin complex such as shelterin(core) would first localize to a ss/ds telomeric DNA junction via TRF2 and POT1 binding (shown here via internal ss-telomeric region). Then the POT1 component would seek the higher affinity $3^{\prime}$ TTAG end, thus protecting the chromosome end. b Dual pathways exist for TPP1 tethering to telomeres, either via TIN2-TRF2 or via POT1, both of which would facilitate telomerase recruitment and its processivity

TRF-containing complexes bound on dsDNA might sequester the POT1-TPP1? (2) Are alternative ways of tethering TPP1 near the telomere $3^{\prime}$ end equivalent in providing enhanced telomerase processivity (3) How should cartoons of the human telomere be drawn, given that TRF1 and TRF2 are homodimers and could plausibly each bind two TIN2 subunits? These questions are addressed below.

The existence of human shelterin as a multi-protein complex is supported by studies in which shelterin complexes were immuno-purified from cultured cell extracts and the presence of shelterin proteins in the complex was identified by specific antibodies ${ }^{7,8}$. Further characterization of these immuno-purified shelterin complexes was not feasible given the limited materials obtained. In this work, we successfully expressed and purified various human shelterin protein complexes to high homogeneity and quantity. We show the human shelterin proteins can stably exist as several protein complexes including TRF2-TIN2-TPP1 ( $\left.\operatorname{shelterin}_{\text {core }}(-\mathrm{POT} 1)\right)$, TIN2-TPP1-POT1 ( $\left.\operatorname{shelterin}_{\text {core }}(-\mathrm{TRF} 2)\right)$, and TRF2-TIN2-TPP1-POT1 ( shelterin $_{\text {core }}$ ).

The double-stranded region of a telomere is several kb long ${ }^{37}$, potentially providing a vast excess of binding sites to sequester the shelterin $_{\text {core }}$ complex away from the few hundred nt singlestranded region. As shown here, the dual-binding mode (ss and ds DNA-binding) property of the shelterin ${ }_{\text {core }}$ complex helps overcome this problem. More specifically, a shelterin complex harboring both TRF2 and POT1 (shelterin core $_{\text {complex) binds }}$ telomeric ss/ds junctions with higher affinity than purely ss or ds telomeric regions, similar to the mouse shelterin complex ${ }^{32}$. This also suggests that shelterin complexes without POT1 will most likely populate the double-stranded telomeric region. Since POT1 is about $\sim 5-10$-fold sub-stoichiometric relative to TRF1 and $\mathrm{TRF}^{30}{ }^{30}$ most of the TRF1 and TRF2-harboring shelterin complexes are unlikely to have POT1 and would bind only to telomeric dsDNA, which is a less stable interaction. This can explain why in live cells, the majority of the TRF1 and TRF2 were highly dynamic, while a fraction of TRF2 had the same slower dynamics as POT1 ${ }^{50}$. It is interesting to note, unlike TRF2, TRF1 did not have a slower dynamic fraction, and this may be explained by the poor connectivity between TRF1 and the rest of shelterin as determined by mass spectrometry ${ }^{47}$.

Because shelterin complexes having both TRF2 and POT1 will likely populate the ss/ds telomeric junction regions, this will effectively position TPP1-POT1-a key functional element of shelterin telomerase regulation-nearer to the $3^{\prime}$ ends. We also

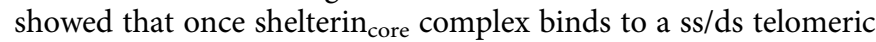
substrate, it is unlikely to move to a single-stranded telomeric DNA. At first glance, this seems like it could potentially sequester TPP1-POT1 from finding the very $3^{\prime}$ ends, but one possible 
model to reconcile the above facts is a "load \& search" model

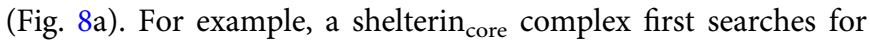
telomeric ss/dsDNA through a three-dimensional diffusion mechanism $^{32}$ (probably through multiple re-engagements) and binds a ss/ds telomeric DNA junction, with POT1 binding to a nearby telomeric ssDNA region (e.g., an internal telomeric ssDNA site). From there, POT1 scans along the telomeric ssDNA until it finds the $3^{\prime}$ end and is stabilized there due to its higher affinity to the $3^{\prime}$ terminal sequence TTAG ${ }^{39}$. Eventually, the $3^{\prime}$ end of the chromosome will be looped back, forming a loop that is bridged by shelterin proteins, unlike a T-loop that is formed by strand-invasion $^{51}$. The model is consistent with the suggestion that TPP1-POT1 can slide along single-stranded DNA ${ }^{52}$. Our off-rate data also showed single-stranded telomeric DNA ending with TTAG is a better competitor than DNA ending with TTAGGG, further supporting the model that the POT1 in the shelterin $_{\text {core }}$ complex will seek higher affinity sites. Because higher-order shelterin complexes such as shelterin core $_{\text {have a }}$ higher propensity to find chromosome $3^{\prime}$ ends, their TPP1 subunit will also serve to recruit telomerase to the $3^{\prime}$ end. Similarly, it will also deliver POT1 to the single-stranded region to inhibit activation of the ATR kinase pathway ${ }^{25}$. Therefore, determining which shelterin sub-complexes exist at telomeres and how they are distributed along telomeres in vivo will be essential in furthering our understanding of shelterin functions.

The TPP1-POT1 heterodimer is sufficient to enhance telomerase processivity in vitro ${ }^{28}$. TPP1 provides the TEL patch that directly interacts with telomerase ${ }^{5,26,53}$, while POT1 brings the TPP1 to telomeric ssDNA ${ }^{29}$. However, in vivo, it appears that recruitment happens the other way around-TPP1 recruits POT1 19,20 -and it is TIN2 that brings TPP1 to the telomere ${ }^{15,36}$. Here we resolve this potentially confusing situation by showing that tethering of TPP1 to the DNA substrate is sufficient for it to be a telomerase processivity factor. This tethering can be accomplished by TIN2-TRF2 or by POT1 (Fig. 8b). Even though we did not include TRF1 in this study, based on our findings, it is reasonable to suggest a shelterin complex such as TRF1-TIN2-TPP1 can be a telomerase processivity factor as well.

Previously POT1-TPP1 was shown to give a 2-3-fold increase in telomerase processivity ${ }^{5}$. These measurements were done with a truncated complex comprised of TPP1-N (amino acids 87-334) plus POT1. Here, we find that the POT1 with the entire TPP1 protein plus the TIN2 subunit increases telomerase processivity about three-fold. Thus, these additional protein domains do not have a substantial effect on stimulation of telomerase processivity. In summary, our study documents a new avenue to achieve telomerase recruitment and processivity by shelterin proteins (Fig. 8b). This pathway, which had not been previously shown in vitro, depends on TPP1 tethering via TRF2-TIN2 but is independent of POT1. This may have relevance to the situation in vivo, where POT1 is not required for shelterin-telomerase interaction $^{15}$. It remains to be determined which pathway telomerase uses for recruitment to telomeres in cells.

In this work, we measured the stoichiometry of a human shelterin complex containing full-length TRF2, RAP1, TIN2, TPP1, and POT1. Interestingly, the TRF2:TIN2 stoichiometry in the context of the protein complex is 2:1 (i.e., one homodimer of TRF2 per TIN2). The unequal 2:1 stoichiometry differs from a previous structural study of the TRF1, TRF2, and TIN2 interaction, which suggested a 1:1 stoichiometry instead ${ }^{14}$. However, the difference could be due to the previous study using peptides instead of full-length proteins as used in this work. Because the TIN2-interacting domain of TRF2 maps in the TRF2 homodimerization domain ${ }^{14}$, it is possible that the conformation of this region of TRF2 only allows a single TIN2 to dock. Furthermore, secondary structure prediction shows that the TIN2 N-terminus has several blocks of alpha helices, which would be more rigid than unstructured peptide and perhaps give steric hindrance, preventing two proteins from docking. An untested assumption is that the stoichiometry of shelterin overexpressed in insect cells predicts the stoichiometry of the natural shelterin complex residing on human chromosome telomeres.

In terms of potential biological implications, the uneven stoichiometry of TRF2-TIN2 effectively reduces the number of TIN2-TPP1-POT1 recruited to telomeres. This can be a mechanism for cells to limit the number of TPP1-POT1 at telomeres and thus directly affects DNA protection and telomerase regulation functions of shelterin. It will be interesting to determine if the TRF1-TIN2 stoichiometry is the same as TRF2-TIN2 and if the TRF1-TIN2-TRF2 trimeric complex has a different stoichiometry due to potential steric hindrance when TIN2 binds both TRF1 and TRF2.

We also identified a TPP1 peptide that can recruit TIN2 independently. Secondary structure prediction shows two 10 amino-acid alpha helices, of which one overlaps with the region TPP $1_{528-533}$ where our NAAIRS mutation affects TIN2 interaction. Further work will be required to elucidate which residue(s) are critical for TIN2 interaction. Since the affinities of TRF1 and TRF2 to the TIN2 peptide have been measured to be $\sim 0.3$ and 6.5 $\mu \mathrm{M}$, respectively ${ }^{14}$, it will be interesting to determine the binding affinity of $\mathrm{TPP}_{480-544}$ to TIN2 and compare the protein-protein affinities. In addition, TPP1-POT1 is sub-stoichiometric relative to TIN2 and TRF2 in cells ${ }^{30}$, making understanding how TPP1 interacts with TIN2 critical for studies of shelterin telomere biology.

Because detailed measurements were not available, published cartoons of the human shelterin complex show different versions of TRF2:TIN2 stoichiometry-one TRF2 per TIN2 ${ }^{1,54}$ or two TRF2 per TIN2 ${ }^{3,55}$. Different cartoons also show one or two RAP1 per TRF2 dimer ${ }^{56-58}$. Based on the stoichiometry of human shelterin expressed in insect cells, pending verification of the stoichiometry of the complex in vivo, we now suggest that these cartoons should be drawn with one TIN2 molecule and two RAP1 molecules per TRF2 dimer. The addition of RAP1 did not affect the TRF2:TIN2 stoichiometry, which remained 2:1.

\section{Methods}

Protein expression. Human TRF1 (NP_059523.2), TRF2 (XP_005256180.1), RAP1 (NP_061848.2), TIN2 (NP_036593.2), TPP1 (AAX82621.1), and POT1 (NP_056265.2) cDNAs were individually cloned into the pFastBacl expression vector (Invitrogen). The TRF1, TRF2, and RAP1 constructs have N-terminal hexahistidine (6XHis) tags while TIN2, TPP1, and POT1 have PreScission-cleavable Nterminal 6XHis-MBP tags. The expression vectors were used to make recombinant baculoviruses based on the protocol established in the Bac-to-Bac Baculovirus Expression System (Invitrogen). The baculovirus stocks were titered by gp64 detection using flow cytometry analysis (Expression Systems). Yield-optimized amounts of baculoviruses were used to infect 2-4 liters of Thi cells (Expression Systems) at a cell density of $1.5-2.0 \times 10^{6} \mathrm{cells} \mathrm{ml}^{-1}$. The infected cells were then incubated in a shaker for $66-72 \mathrm{~h}\left(27^{\circ} \mathrm{C}, 130 \mathrm{rpm}\right)$ before they were collected. The collected cells were either immediately used for protein purification or snap-frozen using liquid nitrogen for later purification.

Purification of shelterin protein complexes. All steps were performed at $4^{\circ} \mathrm{C}$. Cell pellets were disrupted in lysis buffer (50 mM HEPES pH 7.5, $300 \mathrm{mM} \mathrm{NaCl}$, $1 \mathrm{mM}$ DTT, 1\% NP-40, $1 \mathrm{mM}$ PMSF, EDTA-free protease inhibitors (Roche)) and the lysate was clarified by centrifugation. The supernatant was mixed with preequilibrated amylose beads for $4 \mathrm{~h}$. The beads were washed three times with wash buffer (50 mM HEPES 7.5, $300 \mathrm{mM} \mathrm{NaCl}, 1 \mathrm{mM}$ TCEP) before eluting the captured proteins with elution buffer (50 mM HEPES pH 7.5, $300 \mathrm{mM} \mathrm{NaCl}, 1 \mathrm{mM}$ DTT, $10 \mathrm{mM}$ maltose). The eluted proteins were then concentrated to $\sim 10 \mathrm{mg} \mathrm{ml}^{-1}$ before cutting with PreScission protease (GE Healthcare Life Sciences) overnight. The MBP tag cleavage efficiency was checked with SDS-PAGE before exchanging the buffer to low-salt buffer (50 mM HEPES pH 7.5, $150 \mathrm{mM} \mathrm{NaCl}, 1 \mathrm{mM}$ DTT) for anion-exchange chromatography (HiTrap Q HP, $5 \mathrm{ml}$ ) with AKTA explorer FPLC machine (GE Lifesciences). After injecting the sample into the column, the column was washed with $3 \times \mathrm{C} . \mathrm{V}$. of low-salt buffer before eluting with a linear buffer gradient change to $60 \%$ high-salt buffer (50 mM HEPES pH 7.5, $1000 \mathrm{mM}$ 
$\mathrm{NaCl}, 1 \mathrm{mM}$ DTT) over $10 \mathrm{C.V}$. Cleaved MBP tags were removed during the column wash and the tag-free protein complexes were collected during elution phase. SDS-PAGE was used to determine which elution fractions to pool and concentrate. The samples were then injected into a Superose 6 increase 10/300 GL column pre-equilibrated with storage buffer (50 mM HEPES pH 7.5, $300 \mathrm{mM}$ $\mathrm{NaCl}, 1 \mathrm{mM}$ TCEP) for the final SEC purification step. The elution fractions were checked with SDS-PAGE before pooling and concentration. The concentrated proteins $\left(>5 \mathrm{mg} \mathrm{ml}^{-1}\right)$ were then aliquoted and snap-frozen before storage at $-80^{\circ} \mathrm{C}$.

Agarose-electrophoretic mobility shift assay. Radioactive $\left(5^{\prime}-{ }^{32} \mathrm{P}\right)$ DNA substrates (sense-strand labeled) were used for detection. The estimated specific activity is at least 200,000 c.p.m.per pmol. A reaction volume of $10 \mu \mathrm{l}$ was used for the protein-DNA interaction with final 1000 c.p.m. radioactive substrate. The binding buffer was $50 \mathrm{mM}$ Tris-HCl pH 8.0, $150 \mathrm{mM} \mathrm{KCl}, 2 \mathrm{mM} \mathrm{MgCl}_{2}, 1 \mathrm{mM}$ DTT, $10 \%(\mathrm{v} / \mathrm{v})$ glycerol, $0.5 \mathrm{mg} \mathrm{ml}^{-1} \mathrm{BSA}$, and $0.02 \mathrm{mg} \mathrm{ml}^{-1}$ non-specific carrier dsDNA (5'-GACCATGCTTATCCCCATTTGTATCATACAA-3'). The reaction was incubated for $30 \mathrm{~min}$ at $23{ }^{\circ} \mathrm{C}$ before loading onto a $10 \mathrm{~cm} 15$-well $0.7 \%$ agarose gel (SeaKem LE Agarose, Lonza). The electrophoresis buffer was $1 \times$ TBE and the gel was run for $1.5 \mathrm{~h}$ at $7 \mathrm{~V} \mathrm{~cm}^{-1}$ and $4^{\circ} \mathrm{C}$. The gels were then vacuumdried for $1.5 \mathrm{~h}$ at $80^{\circ} \mathrm{C}$ before exposure to phosphor screens. After overnight exposure, the screens were imaged with a Typhoon trio scanner (GE Lifesciences). The analysis of EMSA densitometry was done with Fiji (Distribution of ImageJ) ${ }^{60}$ and data fitted with the Hill equation using OriginPro (OriginLab). Independent replicates (Number of replicates, $n$, is stated in legend for each corresponding figure) were done and the average was fitted. The sequences for single-stranded DNA, ss-TEL is $5^{\prime}$-TTAGGGTTAGGGTTAGGG-3', ss-nonTEL is 5'-GACCATG CTTATCCCCATTTGTATCATACAA- $3^{\prime}$ while double-stranded DNA, ds-TEL is $5^{\prime}$-GACCATGCTTAGGGTTAGGGTTATCATACAA-3' , and ds-nonTEL is $5^{\prime}-\mathrm{G}$ ACCATGCTTATCCCCATTTGTATCATACAA-3'.

Fluorescence polarization. The $\mathrm{C} 8$ substrate sense-strand oligo was synthesized with a $5^{\prime}$ Alexa-488 fluorescent dye (5'-Alex488N-GACCATGCTTAGGGTTAGG GTTATCATACAAGTTAGGGTTAGGG-3') and thermally annealed with the anti-sense strand (5'-TTGTATGATAACCCTAACCCTAAGCATGGTC-3') (Integrated DNA Technologies). Each $40 \mu$ reaction (buffer- $-50 \mathrm{mM}$ Tris- $\mathrm{HCl} \mathrm{pH}$ 8.0, $150 \mathrm{mM} \mathrm{KCl}, 2 \mathrm{mM} \mathrm{MgCl}_{2}, 1 \mathrm{mM}$ DTT, $10 \%$ (v/v) glycerol, $0.5 \mathrm{mg} \mathrm{ml}^{-1}$ BSA) contained $5 \mathrm{nM}(500 \mathrm{nM}$ for saturation-binding assay) fluorescent substrate and was incubated with protein for $30 \mathrm{~min}$ at $23^{\circ} \mathrm{C}$ before fluorescent polarization measurement in a 384-well plate with Synergy 2 multi-mode plate reader (BioTek), For competitor assays, initial measurements were taken (defined as $t=0$ ) before adding competitors and taking measurements every $2 \mathrm{~min}$ for $4 \mathrm{~h}$.

SEC-MALS. All protein samples were filtered with a $0.1 \mu \mathrm{m}$ filter and adjusted to $1 \mathrm{mg} \mathrm{ml}^{-1}$ before injecting (100 $\mu \mathrm{l}$ sample volume) into a pre-equilibrated GE Superose 6 increase 10/300 GL column that was connected to a Wyatt Dawn EOS 18-angle light-scattering detector and Optilab DSP refractive index detector for multi-angle light scattering analysis. The SEC-MALS runs were conducted at $0.5 \mathrm{ml} \mathrm{min}^{-1}$ and $25^{\circ} \mathrm{C}$. The buffer used was $50 \mathrm{mM}$ HEPES pH 7.5, $300 \mathrm{mM} \mathrm{NaCl}$ and $1 \mathrm{mM}$ TCEP. The SEC-MALS analysis was done using Astra software

ybbR-tagged protein CoA-dyes labeling. ybbR tag of amino-acid sequence DSLEFIASKLA was added to the N-termini of TRF2, TPP1, and POT1 and C-terminus of TIN2 in the baculovirus constructs. Expression and purification were done similarly as described in the protein expression and purification sections. The purified protein complexes $(5 \mu \mathrm{M})$ were then labeled with CoA-Cy3 $(10$ $\mu \mathrm{M})$ using recombinant Sfp phosphopantetheinyl transferase $(1 \mu \mathrm{M})$ in final buffer condition of $50 \mathrm{mM}$ HEPES pH 7.5, $300 \mathrm{mM} \mathrm{KCl}, 10 \mathrm{mM} \mathrm{MgCl}_{2}, 1 \mathrm{mM}$ TCEP. After overnight incubation at $4{ }^{\circ} \mathrm{C}$, the labeled protein complex was subjected to SDS-PAGE and the fluorescent gel was scanned with a Typhoon Trio Scanner.

Limited proteolysis of protein complex. Trypsin (Promega) was used for limited proteolysis at 100:1 (protein:trypsin) molar ratio. Trypsin was added to $100 \mu \mathrm{l}$ of $10 \mu \mathrm{M}$ TIN2-TPP1 complex solution with final trypsin concentration of $0.1 \mu \mathrm{M}$. Digested samples were taken out at $0,5,10,30$, and $60 \mathrm{~min}$ and reactions quenched by formic acid addition. The samples were then run on SDS-PAGE to analyze digested protein bands. SDS-PAGE gels were blotted onto a polyvinylidene difluoride (PVDF) membrane and stained with Coomassie Blue for visualization. The transferred bands were excised and sent for Edman sequencing analysis (UC Davis Proteomics Core Facility, USA).

Cell culture. Tni cells (Expression Systems) were cultured as suspension cells at $27^{\circ} \mathrm{C}$ and $130 \mathrm{rpm}$ in ESF 291 medium (Expression Systems) supplemented with a final $5 \mu \mathrm{g} \mathrm{ml}^{-1}$ gentamicin (Sigma-Aldrich). The cell density was maintained at $0.5-3.0 \times 10^{6}$ cells ml $^{-1}$. The U2-OS cells (2-6-3 cell line, a kind gift from David Spector) were cultured as adherent cells at $37^{\circ} \mathrm{C}, 5 \% \mathrm{CO}_{2}$ in DMEM medium supplemented with $2 \mathrm{mM}$ L-glutamine, $1 \%$ penicillin/streptomycin, $100 \mu \mathrm{g} \mathrm{ml}^{-1}$ hygromycin B (for LacO array maintenance), and 10\% fetal bovine serum.
Lacl-LacO array interaction assay. eGFP-TPP1-LacI and mCherry-TIN2Sexpressing plasmids were co-transfected into the U2-OS cells containing the $\mathrm{LacO}$ array (grown on 24-well glass plates) using jetPRIME (Polyplus transfection) transfection reagent per manufacturer's protocol. Twenty-four hours after transfection, the cells were washed twice with PBS and then fixed with $0.4 \%(\mathrm{v} / \mathrm{v})$ paraformaldehyde in PBS for $5 \mathrm{~min}$ at room temperature. The cells were permeabilized for $5 \mathrm{~min}$ with $0.01 \%$ Triton-X 100 in PBS and finally stained with DAPI. The fixed cells were than imaged for DAPI, GFP and mCherry fluorescence. Colocalization analysis was performed with $\mathrm{JACoP}^{60}$ (a ImageJ plugin).

Biotinylated peptide pull-down assay. For the purification of recombinant MBP-TIN2, the full sequence DNA was amplified from human cDNA by PCR and cloned into the E. coli expression vector pET28 (Novagen). The resulting MBP-TIN2 was expressed by IPTG induction $\left(0.1 \mathrm{mM}, 18^{\circ} \mathrm{C}\right.$ overnight $)$ in E. coli Rosetta 2(DE3) (Novagen) and purified with amylose affinity chromatography followed by FPLC (previously described). For the peptide pull-down assay, peptides-wt TPP1, NAAIRS 492 and NAAIRS 528 mutants based on TPP1 $1_{480-544}$ (GAQEPCSV...GSEPTPM)-were synthesized as C-terminal biotinylated peptides (Zhongping Tan \& Xiaoyang Guan, CU Boulder, USA). The biotinylated peptides $(10 \mu \mathrm{M})$ were incubated with MBP-TIN2 $(10 \mu \mathrm{M})$ in storage buffer for $30 \mathrm{~min}$ at RT before mixing with streptavidin beads (Thermofisher Scientific) for another $30 \mathrm{~min}$. The beads were washed $3 \times$ with storage buffer to remove uncaptured complexes before eluting by boiling at $95^{\circ} \mathrm{C}$ for $5 \mathrm{~min}$. The input and elute samples were subjected to SDS-PAGE analysis.

Telomerase purification and telomerase direct assay. Plasmids expressing hTR and hTERT, a gift from J. Lingner (EPFL, Lausanne, Switzerland), were transiently transfected into HEK 293T cells with Lipofectamine 2000 reagent (Invitrogen). The over-expressed human telomerase was purified as previously described $^{59}$. Shelterin protein complexes varied between 0 and $100 \mathrm{nM}$ as indicated in figures. Double-stranded oligonucleotide substrate C8a was at 1 or $10 \mathrm{nM}$. Conditions for assays were $50 \mathrm{mM}$ Tris- $\mathrm{HCl} \mathrm{pH} 8.0,50 \mathrm{mM} \mathrm{KCl}(15 \mathrm{mM}$ brought in with telomerase, $35 \mathrm{mM}$ added), $30 \mathrm{mM} \mathrm{NaCl}$ (brought in with shelterin complexes), $2 \mathrm{mM} \mathrm{MgCl}_{2}, 1 \mathrm{mM}$ spermidine, $5 \mathrm{mM} \mu$-mercaptoethanol, $0.33 \mu \mathrm{M}$ ${ }^{32} \mathrm{P}$-dGTP $\left(3000 \mathrm{Ci} \mathrm{mmol}^{-1}\right.$ ), $2.9 \mu \mathrm{M}$ cold dGTP, $0.5 \mathrm{mM}$ dATP, and $0.5 \mathrm{mM}$ TTP.

Prior to starting telomerase extension, the protein complexes, human telomerase and substrate oligo were incubated at RT for $30 \mathrm{~min}$. To start reaction, $3 \mu \mathrm{l}$ of dNTP mix was added. Tubes were placed at $30^{\circ} \mathrm{C}$ for $1 \mathrm{~h}$. The reaction was stopped by the addition of $100 \mu \mathrm{l} 3.6 \mathrm{M} \mathrm{NH}_{4} \mathrm{Ac}$ containing $20 \mu \mathrm{g}$ glycogen, and 3000 c.p.m. of each of three oligonucleotide loading controls, LC1, LC2, and LC3. Following the addition of $500 \mu \mathrm{l}$ of ethanol, samples were placed at $-80^{\circ} \mathrm{C}$ overnight. Products were pelleted at $15 \mathrm{~K} \mathrm{r.p.m}$. for $15 \mathrm{~min}$ at $4{ }^{\circ} \mathrm{C}$. After washing the pellet with $1000 \mu \mathrm{l}$ of $-20^{\circ} \mathrm{C} 70 \%$ ethanol, the pellet was dried and then dissolved in $11 \mu \mathrm{l}$ water plus $11 \mu \mathrm{l}$ Sample prep buffer $(0.1 \times \mathrm{TBE}$, $93 \%$ Formamide, $50 \mathrm{mM}$ EDTA, $0.05 \%$ Bromophenol blue, and $0.05 \%$ Xylene cyanol). An aliquot of $10 \mu \mathrm{l}$ of each sample was loaded on a $10 \%$ acrylamide $7 \mathrm{M}$ urea sequencing gel, prerun for $45 \mathrm{~min}$ at $90 \mathrm{~W}$ (constant). The gels were run for $1 \mathrm{~h} 45 \mathrm{~min}$ (short run) or $2 \mathrm{~h} 45 \mathrm{~min}$ (long run) at $90 \mathrm{~W}$. Gels were dried and exposed to a phosphor screen before scanning.

Data Availability. The data that support the findings of this study are available from the corresponding author upon reasonable request.

Received: 16 August 2017 Accepted: 7 September 2017 Published online: 20 October 2017

\section{References}

1. Lange, T. de. Shelterin: the protein complex that shapes and safeguards human telomeres. Genes Dev. 19, 2100-2110 (2005).

2. Sfeir, A. \& Lange, T. de. Removal of shelterin reveals the telomere endprotection problem. Science 336, 593-597 (2012).

3. Hockemeyer, D. \& Collins, K. Control of telomerase action at human telomeres. Nat. Struct. Mol. Biol. 22, 848-852 (2015).

4. Nandakumar, J. \& Cech, T. R. Finding the end: recruitment of telomerase to telomeres. Nat. Rev. Mol. Cell. Biol. 14, 69-82 (2013).

5. Nandakumar, J. et al. The TEL patch of telomere protein TPP1 mediates telomerase recruitment and processivity. Nature 492, 285-289 (2012).

6. Frank, A. K. et al. The Shelterin TIN2 subunit mediates recruitment of telomerase to telomeres. PLoS Genet. 11, e1005410 (2015).

7. O'Connor, M. S., Safari, A., Xin, H., Liu, D. \& Songyang, Z. A critical role for TPP1 and TIN2 interaction in high-order telomeric complex assembly. Proc. Natl Acad. Sci. USA 103, 11874-11879 (2006).

8. Liu, D., O'Connor, M. S., Qin, J. \& Songyang, Z. Telosome, a mammalian telomere-associated complex formed by multiple telomeric proteins. J. Biol. Chem. 279, 51338-51342 (2004).

9. Bianchi, A., Smith, S., Chong, L., Elias, P. \& de Lange, T. TRF1 is a dimer and bends telomeric DNA. EMBO J. 16, 1785-1794 (1997). 
10. Broccoli, D., Smogorzewska, A., Chong, L. \& de Lange, T. Human telomeres contain two distinct Myb-related proteins, TRF1 and TRF2. Nat. Genet. 17, 231-235 (1997)

11. Fairall, L., Chapman, L., Moss, H., de Lange, T. \& Rhodes, D. Structure of the TRFH dimerization domain of the human telomeric proteins TRF1 and TRF2. Mol. Cell 8, 351-361 (2001).

12. Court, R., Chapman, L., Fairall, L. \& Rhodes, D. How the human telomeric proteins TRF1 and TRF2 recognize telomeric DNA: a view from highresolution crystal structures. EMBO Rep. 6, 39-45 (2005).

13. Ye, J. Z.-S. et al. TIN2 binds TRF1 and TRF2 simultaneously and stabilizes the TRF2 complex on telomeres. J. Biol. Chem. 279, 47264-47271 (2004).

14. Chen, Y. et al. A shared docking motif in TRF1 and TRF2 used for differential recruitment of telomeric proteins. Science 319, 1092-1096 (2008).

15. Abreu, E. et al. TIN2-tethered TPP1 recruits human telomerase to telomeres in vivo. Mol. Cell. Biol. 30, 2971-2982 (2010).

16. Baumann, P. \& Cech, T. R. Pot1, the putative telomere end-binding protein in fission yeast and humans. Science 292, 1171-1175 (2001).

17. Lei, M., Podell, E. R. \& Cech, T. R. Structure of human POT1 bound to telomeric single-stranded DNA provides a model for chromosome endprotection. Nat. Struct. Mol. Biol. 11, 1223-1229 (2004).

18. Loayza, D., Parsons, H., Donigian, J., Hoke, K. \& de Lange, T. DNA binding features of human POT1: a nonamer 5'-TAGGGTTAG-3' minimal binding site, sequence specificity, and internal binding to multimeric sites. J. Biol. Chem. 279, 13241-13248 (2004).

19. Liu, D. et al. PTOP interacts with POT1 and regulates its localization to telomeres. Nat. Cell Biol. 6, 673-680 (2004)

20. Ye, J. Z.-S. et al. POT1-interacting protein PIP1: a telomere length regulator that recruits POT1 to the TIN2/TRF1 complex. Genes Dev. 18, 1649-1654 (2004).

21. Janoušková, E. et al. Human Rap1 modulates TRF2 attraction to telomeric DNA. Nucleic Acids Res. 43, 2691-2700 (2015).

22. Chen, Y. et al. A conserved motif within RAP1 has diversified roles in telomere protection and regulation in different organisms. Nat. Struct. Mol. Biol. 18, 213-221 (2011).

23. Karlseder, J. et al. The telomeric protein TRF2 binds the ATM kinase and can inhibit the ATM-dependent DNA damage response. PLoS Biol. 2, E240 (2004).

24. Karlseder, J., Broccoli, D., Dai, Y., Hardy, S. \& Lange, T. de. p53- and ATMdependent apoptosis induced by telomeres lacking TRF2. Science 283, 1321-1325 (1999).

25. Denchi, E. L. \& de Lange, T. Protection of telomeres through independent control of ATM and ATR by TRF2 and POT1. Nature 448, 1068-1071 (2007).

26. Zhong, F. L. et al. TPP1 OB-fold domain controls telomere maintenance by recruiting telomerase to chromosome ends. Cell 150, 481-494 (2012).

27. Schmidt, J. C., Dalby, A. B. \& Cech, T. R. Identification of human TERT elements necessary for telomerase recruitment to telomeres. eLife 3, e03563 (2014).

28. Wang, F. et al. The POT1-TPP1 telomere complex is a telomerase processivity factor. Nature 445, 506-510 (2007).

29. Latrick, C. M. \& Cech, T. R. POT1-TPP1 enhances telomerase processivity by slowing primer dissociation and aiding translocation. EMBO J. 29, 924-933 (2010).

30. Takai, K. K., Hooper, S., Blackwood, S., Gandhi, R. \& de Lange, T. In vivo stoichiometry of shelterin components. J. Biol. Chem. 285, 1457-1467 (2010).

31. Amiard, S. et al. A topological mechanism for TRF2-enhanced strand invasion. Nat. Struct. Mol. Biol. 14, 147-154 (2007).

32. Erdel, F. et al. Telomere recognition and assembly mechanism of mammalian shelterin. Cell Rep. 18, 41-53 (2017).

33. Choi, K. H., Farrell, A. S., Lakamp, A. S. \& Ouellette, M. M. Characterization of the DNA binding specificity of Shelterin complexes. Nucleic Acids Res. 39, 9206-9223 (2011)

34. Doksani, Y., Wu, J. Y., de Lange, T. \& Zhuang, X. Super-resolution fluorescence imaging of telomeres reveals TRF2-dependent t-loop formation. Cell 155, 345-356 (2013)

35. Frescas, D. \& de Lange, T. TRF2-Tethered TIN2 can mediate telomere protection by TPP1/POT1. Mol. Cell Biol. 34, 1349-1362 (2014).

36. Takai, K. K., Kibe, T., Donigian, J. R., Frescas, D. \& de Lange, T. Telomere protection by TPP1/POT1 requires tethering to TIN2. Mol. Cell 44, 647-659 (2011).

37. Moyzis, R. K. et al. A highly conserved repetitive DNA sequence, (TTAGGG)n, present at the telomeres of human chromosomes. Proc. Natl Acad. Sci. USA 85, 6622-6626 (1988).

38. Wright, W. E., Tesmer, V. M., Huffman, K. E., Levene, S. D. \& Shay, J. W. Normal human chromosomes have long G-rich telomeric overhangs at one end. Genes Dev. 11, 2801-2809 (1997).

39. Sfeir, A. J., Chai, W., Shay, J. W. \& Wright, W. E. Telomere-end processing. Mol. Cell 18, 131-138 (2005).

40. Yin, J. et al. Genetically encoded short peptide tag for versatile protein labeling by Sfp phosphopantetheinyl transferase. Proc. Natl Acad. Sci. USA 102, 15815-15820 (2005)
41. Chen, L.-Y. et al. Mitochondrial localization of telomeric protein TIN2 links telomere regulation to metabolic control. Mol. Cell 47, 839-850 (2012).

42. Wilson, I. A. et al. Identical short peptide sequences in unrelated proteins can have different conformations: a testing ground for theories of immune recognition. Proc. Natl Acad. Sci. USA 82, 5255-5259 (1985).

43. Janicki, S. M. et al. From silencing to gene expression: real-time analysis in single cells. Cell 116, 683-698 (2004).

44. Smogorzewska, A. et al. Control of human telomere length by TRF1 and TRF2 Mol. Cell Biol. 20, 1659-1668 (2000).

45. Lei, M., Zaug, A. J., Podell, E. R. \& Cech, T. R. Switching human telomerase on and off with hPOT1 protein in vitro. J. Biol. Chem. 280, 20449-20456 (2005).

46. Bae, N. S. \& Baumann, P. A RAP1/TRF2 complex inhibits nonhomologous end-joining at human telomeric DNA ends. Mol. Cell 26, 323-334 (2007).

47. Giannone, R. J. et al. The protein network surrounding the human telomere repeat binding factors TRF1, TRF2, and POT1. PLoS ONE 5, e12407 (2010).

48. Rai, R., Chen, Y., Lei, M. \& Chang, S. TRF2-RAP1 is required to protect telomeres from engaging in homologous recombination-mediated deletions and fusions. Nat. Commun. 7, 10881 (2016).

49. Arat, N. Ö. \& Griffith, J. D. Human Rap1 interacts directly with telomeric DNA and regulates TRF2 localization at the telomere. J. Biol. Chem. 287, 41583-41594 (2012).

50. Mattern, K. A. et al. Dynamics of protein binding to telomeres in living cells: implications for telomere structure and function. Mol. Cell Biol. 24, 5587-5594 (2004).

51. Griffith, J. D. et al. Mammalian telomeres end in a large duplex loop. Cell $\mathbf{9 7}$ 503-514 (1999).

52. Hwang, H., Buncher, N., Opresko, P. L. \& Myong, S. POT1-TPP1 regulates telomeric overhang structural dynamics. Structure 20, 1872-1880 (2012).

53. Sexton, A. N., Youmans, D. T. \& Collins, K. Specificity requirements for human telomere protein interaction with telomerase holoenzyme. J. Biol. Chem. 287, 34455-34464 (2012).

54. Verdun, R. E. \& Karlseder, J. Replication and protection of telomeres. Nature 447, 924-931 (2007).

55. O’Sullivan, R. J. \& Karlseder, J. Telomeres: protecting chromosomes against genome instability. Nat. Rev. Mol. Cell. Biol. 11, 171-181 (2010).

56. Denchi, E. L. Give me a break: how telomeres suppress the DNA damage response. DNA Repair 8, 1118-1126 (2009).

57. Xu, Y. Chemistry in human telomere biology: structure, function and targeting of telomere DNA/RNA. Chem. Soc. Rev. 40, 2719-2740 (2011).

58. Maciejowski, J. \& de Lange, T. Telomeres in cancer: tumour suppression and genome instability. Nat. Rev. Mol. Cell. Biol. 18, 175-186 (2017).

59. Cristofari, G. \& Lingner, J. Telomere length homeostasis requires that telomerase levels are limiting. EMBO J. 25, 565-574 (2006).

60. Bolte, S. \& Cordelières, F. P. A guided tour into subcellular colocalization analysis in light microscopy. J. Microsc. 224, 213-232 (2006).

\section{Acknowledgements}

We thank Annette Erbse (Biochemistry Instrument Core, University of Colorado Boulder) for initial help and discussion on setting up the SEC-MALS and CD spectroscopy experiments, Xiaoyang Guan and Zhongping Tan (University of Colorado Boulder) for synthesizing the biotinylated TPP1 peptides, Thomas Lee (Central Analytical Mass Spectrometry Facility, University of Colorado Boulder) for assisting in MALDI experiments, John Schulze (Proteomics Core Facility, University of California Davis) for performing the Edman sequencing analysis and the Cech lab members for helpful discussions. T.R.C. is an investigator of the Howard Hughes Medical Institute. This work was supported in part by a grant from the NIH to T.R.C. (GM099705). Shared instrument pool (for CD and SEC-MALS) and Grant number (1S10RR028036-01).

\section{Author contributions}

C.L. and T.R.C. designed the experiments. C.L. and H.K. carried out the protein expression/purification, peptide pull-down, and SEC-MALS experiments. C.L. carried out the gel-binding, fluorescence polarization, CD spectroscopy, and LacO-LacI experiments. A.J.Z. carried out the telomerase purification and direct telomerase assays. C.L. and T.R.C. wrote the manuscript.

\section{Additional information}

Supplementary Information accompanies this paper at https://doi.org/10.1038/s41467 017-01313-w.

Competing interests: T.R.C. is on the board of directors of Merck, Inc., which provided no funding for this study. The remaining authors declare no competing financial interests. 
Reprints and permission information is available online at http://npg.nature.com/ reprintsandpermissions/

Publisher's note: Springer Nature remains neutral with regard to jurisdictional claims in published maps and institutional affiliations.

(c) (i) Open Access This article is licensed under a Creative Commons Attribution 4.0 International License, which permits use, sharing, adaptation, distribution and reproduction in any medium or format, as long as you give appropriate credit to the original author(s) and the source, provide a link to the Creative Commons license, and indicate if changes were made. The images or other third party material in this article are included in the article's Creative Commons license, unless indicated otherwise in a credit line to the material. If material is not included in the article's Creative Commons license and your intended use is not permitted by statutory regulation or exceeds the permitted use, you will need to obtain permission directly from the copyright holder. To view a copy of this license, visit http://creativecommons.org/ licenses/by/4.0/.

(C) The Author(s) 2017 